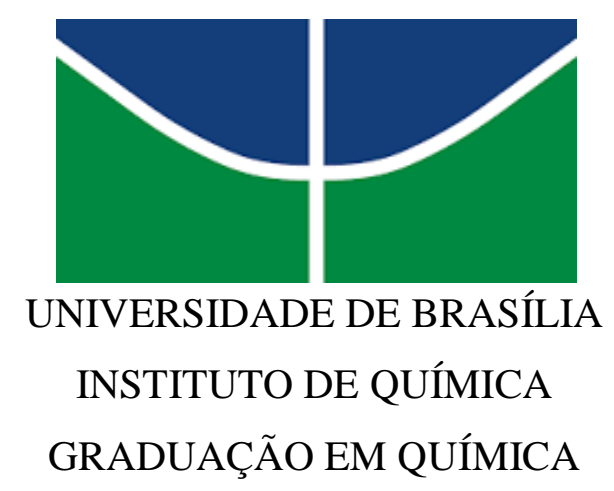

TRABALHO DE CONCLUSÃO DE CURSO

SÍNTESE E CARACTERIZAÇÃO DE COMPOSTOS INÉDITOS DERIVADOS DA VITAMINA K3

MIGUEL DE FREITAS MUNIZ

ORIENTADORA: PROF ${ }^{\mathrm{a}} \mathrm{Dr}^{\mathrm{a}}$ CLAUDIA CRISTINA GATTO

BRASÍLIA - DF, BRASIL

$1 \% / 2019$ 


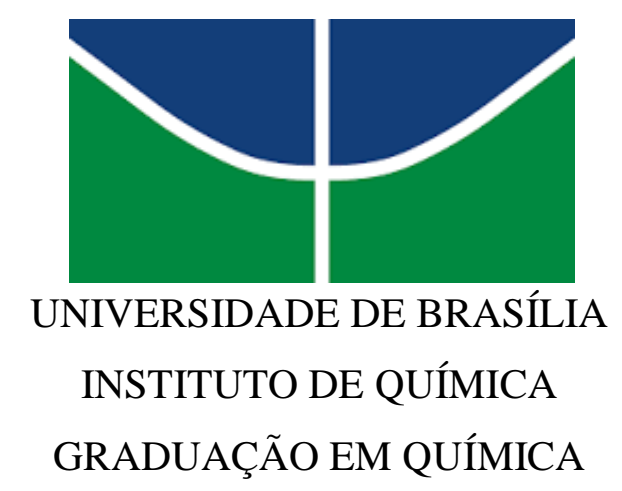

TRABALHO DE CONCLUSÃO DE CURSO

\title{
SÍNTESE E CARACTERIZAÇÃO DE COMPOSTOS INÉDITOS DERIVADOS DA VITAMINA K3
}

\begin{abstract}
Trabalho de Conclusão de Curso apresentado ao Instituto de Química da Universidade de Brasília como requisito parcial para conclusão do curso de Bacharelado em Química.
\end{abstract}

MIGUEL DE FREITAS MUNIZ

ORIENTADORA: PROF ${ }^{\mathrm{a}} \mathrm{Dr}^{\mathrm{a}}$ CLAUDIA CRISTINA GATTO

BRASÍLIA - DF, BRASIL $1 \% 2019$ 


\section{Agradecimentos}

Agradeço, primeiramente, aos meus pais, que sempre me deram todo o suporte necessário;

Agradeço também aos colegas do Laboratório de Síntese Inorgânica e Cristalografia por toda a ajuda no processo de confecção desse trabalho;

Agradeço à minha namorada por tudo;

Agradeço aos professores da banca pela oportunidade e apoio;

Agradeço à minha orientadora por sempre ser tão solícita e por toda a compreensão.

Muito obrigado. 


\section{Resumo}

As semicarbazonas e tiossemicarbazonas compõem a classe de compostos orgânicos das bases de Schiff, que apresentam grande interesse devido à sua capacidade de atuarem como agentes quelantes na área de química de coordenação. Elas também demonstram um amplo espectro de ações farmacológicas, que pode ser otimizado através da inserção de biomoléculas em sua estrutura e por sua coordenadação a centros metálicos. Este trabalho descreve a síntese, análise estrutural e espectroscópica de um ligante semicarbazona inédito derivado da vitamina $\mathrm{K} 3$, o K3Phsz (menadiona fenil-semicarbazona), tendo como foco principal a obtenção de produto cristalino adequado para a utilização do método de difração de raios $\mathrm{X}$ de monocristal de forma a avaliar os modos de coordenação apresentados pelo átomo metálico, possíveis arranjos moleculares e características estruturais do composto sintetizado. As análises feitas são fundamentais na elucidação da estrutura cristalina do ligante e confirmam a existência do tautômero esperado para o composto. 


\begin{abstract}
Semicarbazones and thiosemicarbazones are a part of a class of organic compounds named Schiff bases, which have great study value due their ability to act as chelating agents in the area of coordination chemistry. They can also demonstrate a broad pharmacological activity that can be enhanced through the insertion of biomolecules in its structure or coordination to metallic centers. This inquiry describes the synthesis, structural and spectroscopic analysis of a new semicarbazone ligand derivaded from vitamin K3, the K3Phsz (menadione phenylsemicarbazone) having as main focus to obtain a crystalline product suitable for the monocrystal X-ray diffraction method and posterior analysis of the coordination modes presented by the metal atom, possible molecular arrangements and structural characteristics of the synthesized compounds. The data obtained is fundamental in the ligand crystaline structure elucidation and confirms the existance of the tautometer expected for this compound.
\end{abstract}




\section{SUMÁRIO}

Resumo

.4

Abstract .5

Lista de .7

Figuras

Lista de . .9

Tabelas

Lista de

Siglas e

Abreviaturas

1.Introdução

e Revisão

Bibliográfica

2.Objetivos

3.Materiais e

Métodos

4.Resultados

e Discussão

5.Conclusão

e

Perspectivas

6.Referências 


\section{LISTA DE FIGURAS}

Figura 1.1. Representação da estrutura geral das semicarbazonas (grupos $\mathrm{R}=\mathrm{H}, \ldots . . . . . . . . . . . . . . . . . . . . . . .13$ grupos alquilas ou arilas

Figura 1.2. Representação da estrutura cristalina do complexo............................13 $\left[\mathrm{Cu}_{2}(\mathrm{bpfsc})_{2}(\mathrm{OAc})_{2}\right]$

Figura 1.3. Representação da estrutura geral das tiossemicarbazonas (grupos R .14 $=\mathrm{H}$, grupos alquilas ou arilas)

Figura 1.4. Representação das estruturas cristalinas dos complexos (a)............................16 $[\mathrm{Cu}(\mathrm{Am} 4 \mathrm{M})(\mathrm{OAc})]$ e (b) $\left[\mathrm{Zn}(\mathrm{HAm} 4 \mathrm{M}) \mathrm{Cl}_{2}\right]$

Figura 1.5. Representação da estrutura molecular da vitamina K3 (menadiona)

Figura 1.6. Representação da estrutura cristalina e molecular do composto $\left[\mathrm{AuPEt}_{3}\left(\mathrm{~K}_{3} \mathrm{tsc}\right)\right]$

Figura 1.7. Projeção estrutural do composto $\left[\mathrm{Cu}(\mathrm{pltsc})\left(\mathrm{H}_{2} \mathrm{O}\right)_{2}\right] \mathrm{SO}_{4}$ .19

Figura 1.8. Representação da estrutura cristalina dos complexos (a)..........................20 $\left[\mathrm{Cu}\left(\mathrm{Me}_{2} \mathrm{tsc} 1\right) \mathrm{Cl}\right]$ e $(\mathbf{b})\left[\mathrm{Cu}\left(\mathrm{Me}_{2} \mathrm{tsc} 2\right) \mathrm{Cl}\right]_{2} 10$

Figura 1.9. Projeção da estrutura cristalina do composto $\left[\mathrm{Cu}(\mathrm{Ettsc}) \mathrm{Cl}_{2} \mathrm{Cl}_{2}{ }^{40}\right.$ Íons $\mathrm{Cl}^{-}$omitidos da figura por motivo de clareza 10

Figura 1.10. Representação da estrutura dos complexos (a) $\left[\mathrm{Zn}(\mathrm{Hasc})_{2}\right]\left(\mathrm{NO}_{3}\right)$ .22 (íons nitrato omitido da figura por motivo de clareza) e (b) [ $\left.\mathrm{ZnCl}_{2}(\mathrm{Hasc})\right]$

Figura 3.1. Estrutura da menadiona .26

Figura 3.2. Esquema mecanístico proposto da formação do ligante $\mathrm{K} 3 \mathrm{Phsz}$ .27

Figura 4.1. Representação estrutural do ligante K3phsz. Elipsóides térmicos .32 representados a um nível de $30 \%$ de probabilidade

Figura 4.2. (a) Representação da cela unitária do composto K3Phsz no plano $b c$ .33

(b) Diagrama referente ao grupo espacial $\mathrm{P} 2{ }_{1} / \mathrm{n}$ da International Tables for Crystallograph ${ }^{45}$

Figura 4.3. Representação das interações intermoleculares do ligante K3Phsz .35

Figura 4.4. Superfície de Hirshfeld mapeada no $d_{\text {norm }}$ para o ligante K3Phsz, .36 (vista de frente)

Figura 4.5. Superfície de Hirshfeld mapeada no $d_{\text {norm }}$ para o ligante $\mathbf{K} \mathbf{3 P h s z}$ .36 (vista de costas)

Figura 4.6. Espectro de FT-IR do ligante K3Phsz 
Figura 4.7. Espectro de absorção molecular na região do ultravioleta-visível............................39 para o ligante K3Phsz nos solventes $\mathrm{MeOH}$ e DMF (concentração de $1 \times 10^{-5}$ $\mathrm{mol} / \mathrm{L})$

Figura 4.8. Espectro de ${ }^{1} \mathrm{H}$ RMN do ligante K3Phsz . .40 


\section{LISTA DE TABELAS}

Tabela 4.1. Dados de ponto de fusão, rendimento e análise elementar de K3Phsz

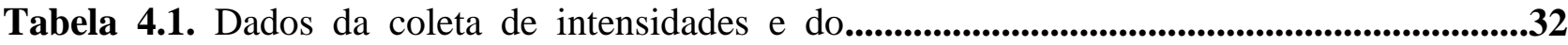

refinamento da estrutura cristalina e molecular do composto K3Phsz

Tabela 4.2. Comprimentos e ângulos de ligação........................................................................34 selecionados para o composto K3Phsz

Tabela 4.2. Frequências de estiramento, em $\mathrm{cm}^{-1}$, e...

deformação angular dos modos de vibração

selecionados para o composto K3Phsz 


\section{LISTA DE SIGLAS E ABREVIATURAS}

SZs - semicarbazonas

TZs - tiossemicarbazonas

bpfsc - benzoilpiridina fenil-semicarbazona

HAm4M - (Z)-2-(amino(piridina-2-il)metileno)-N-metilhidrazinobarbotiamida

$\mathrm{K}_{3}$ tsc- menadiona-tiossemicarbazona

pltsc - piridoxal- tiossemicarbazona

$\mathrm{K}_{3} \mathrm{Phsz}$ - menadiona fenil-semicarbazona

$\mathrm{MeOH}-$ metanol

EtOH - etanol

Ac - acetato

DMF - N,N-dimetilformamida

FT-IR - infravermelho por transformada de Fourier

HS - superfície de Hirshfeld

p.f. - ponto de fusão 


\section{INTRODUÇÃO E REVISÃO BIBLIOGRÁFICA}




\section{Introdução e Revisão Bibliográfica}

Segundo definição da própria International Union of Pure and Applied Chemistry (IUPAC), a Química Medicinal é uma área da química que se utiliza de outras áreas da ciência, como a biologia, a medicina e a farmácia, buscando a descoberta, a preparação e a identificação de compostos biologicamente ativos, bem como, o estudo e a interpretação dos mecanismos de ação a nível molecular e da relação entre a estrutura química e o caráter farmacêutico desses compostos. ${ }^{1}$

A Química Bioinorgânica Medicinal é uma ramificação dessa área caracterizada pelo estudo de íons metálicos, seus complexos e sua atividade em sistemas biológicos. Estudos nessa área observaram que a atividade biológica dos complexos é relacionada aos metais, à atividade dos seus ligantes e sua geometria. Devido a isso, vários compostos vêm sendo sintetizados a fim de serem utilizados no tratamento de diversas doenças. ${ }^{2,3}$

O uso de compostos inorgânicos como fármacos é relatado desde a antiguidade, mas foi no século XX, com a descoberta, por Paul Enrich, de novos compostos de arsênio e sua utilização no tratamento da sífilis ${ }^{4}$ e da utilização do complexo cis-diaminodicloridoplatina (II), de nome comercial "cisplatina", para tratamento do câncer que os estudos nessa área se intensificaram e ganharam destaque. Vários complexos metálicos com atividade farmacológica já foram produzidos e são utilizados no diagnóstico e tratamento de variadas doenças, como complexos de ouro, para artrite reumatóide, complexos de prata com potencial antibacteriano e compostos de gadolínio, usados como agentes de contraste no imageamento por ressonância magnética nuclear. ${ }^{5-}$ 7

As bases de Schiff, caracterizadas por um grupo imínico $\left(\mathrm{R}_{2} \mathrm{C}=\mathrm{NR}\right.$ '), despertam grande interesse em diversas áreas pela sua estabilidade, por possuírem elevado potencial enquanto quelantes e ampla aplicação biológica. ${ }^{8}$ Bases de Schiff derivadas de vitaminas vêm sendo amplamente estudadas pois quando complexadas a centros metálicos têm sua absorção em células otimizada, além de aumentar sua estabilidade, conferindo assim alto potencial como agentes quimioterápicos. $^{9}$

Estudos recentes mostram que, quando complexados a metais de transição como $\mathrm{Cu}(\mathrm{I}) \mathrm{e}$ (II), $\mathrm{Ni}(\mathrm{II}), \mathrm{Au}(\mathrm{I})$ e (III), entre outros metais de transição, as bases de Schiff podem ser mais ativas que os ligantes em suas formas livres, pois os complexos podem otimizar a ação dos ligantes e os centros metálicos podem estar envolvidos no mecanismo da ação biológica ou atuar como transportadores dos ligantes. ${ }^{10-12}$

As semicarbazonas (SZs) são conhecidas como bases de Schiff e apresentam grande interesse na área da química de coordenação e bioinorgânica devido ao seu grande potencial 
quelante e ampla aplicação farmacêutica, como atividade antibacteriana, antifúngica, antihipertensiva e anticonvulsiva. Esses agentes complexantes e seus complexos metálicos também possuem caráter anti-protozoário. ${ }^{13}$ Essas características se devem, principalmente, à grande variação na estereoquímica desses compostos, bem como, aos variados modos de coordenação possíveis via átomo de oxigênio e átomo de nitrogênio azometínico.

A estrutura geral das SZs encontra-se representada na Figuras 1.1. Esses ligantes podem se coordenar aos centros metálicos na forma neutra ou aniônica, tendo essas possibilidades de coordenação otimizadas pela adição de aldeídos e cetonas substituídos, que contém átomos doadores adicionais. Esses compostos podem apresentar um equilíbrio ceto-enólico em solução, conhecido como isometria tautomérica, como também, isomeria conformacional em relação à posição da ligação dupla da imina e a posição da ligação dupla da carbonila. ${ }^{13}$

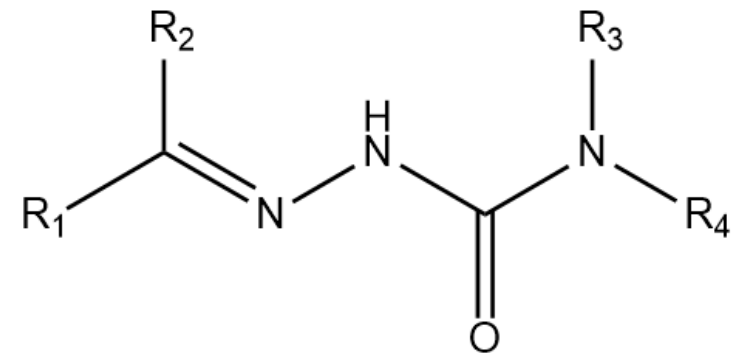

Figura 1.1. Representação da estrutura geral das semicarbazonas (grupos $R=H$, grupo alquila ou arila).

Prathapachandra Kurup e colaboradores ${ }^{13}$, em 2010, publicaram acerca da síntese, caracterização e estrutura cristalina de um complexo de $\mathrm{Cu}(\mathrm{II})$ com o ligante 2-benzoilpiridinaN(4)-fenilsemicarbazona (bpfsc), representado na Figura 1.2.

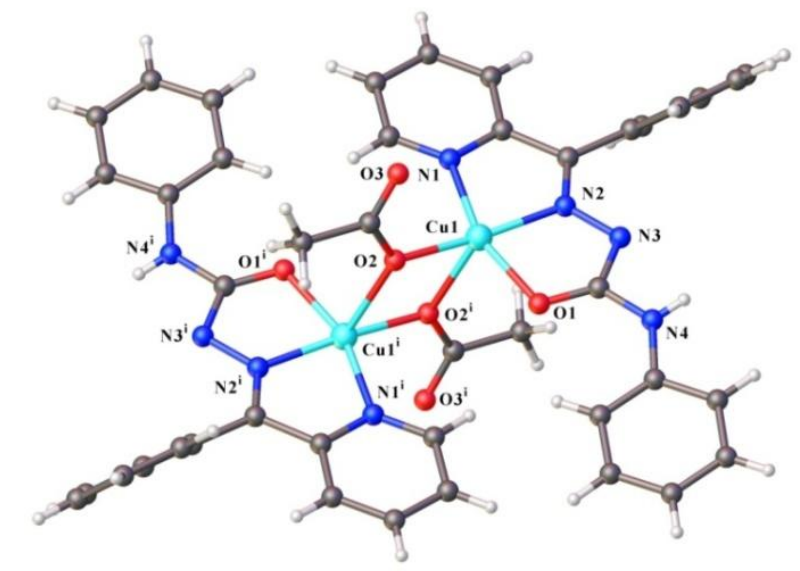

Figura 1.2. Representação da estrutura cristalina do complexo $\left[\mathrm{Cu}_{2}(\mathrm{bpfsc})_{2}(\mathrm{OAc})_{2}\right]{ }^{13}$ 
A análise por difração de raios $X$ mostra que o complexo em questão existe como um dímero ligado por um átomo de oxigênio em ponte de um acetato. Esse composto cristaliza no sistema cristalino monoclínico e grupo espacial $\mathrm{P} 2{ }_{1} / n$. A cela unitária desse composto é constituída por quatro unidades assimétricas.

A estrutura do complexo contém dois centros metálicos onde cada centro está pentacoordenado através dos átomos de nitrogênio azometínico (N2), nitrogênio piridínico (N1), oxigênio do enolato $(\mathrm{O} 1)$ e os átomos de oxigênio $(\mathrm{O} 2, \mathrm{O} 2 \mathrm{~A})$ do grupo acetato. $\mathrm{O}$ composto exibe uma geometria de pirâmide de base quadrada com a base ocupada pelo oxigênio do acetato $(\mathrm{O} 2)$ e pelo ligante semicarbazona. O oxigênio (O2A) do grupo acetato do monômero adjacente se liga na posição axial, formando um dímero com uma separação $\mathrm{Cu}-\mathrm{Cu}$ de aproximadamente $3.422 \AA$. A

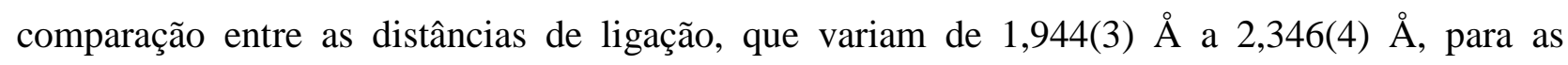
ligações entre $\mathrm{Cu}(1)-\mathrm{O}(2), \quad \mathrm{Cu}(1)-\mathrm{O}(2 \mathrm{~A}), \quad \mathrm{Cu}(1 \mathrm{~A})-\mathrm{O}(2)$ e $\mathrm{Cu}(1 \mathrm{~A})-\mathrm{O}(2 \mathrm{~A})$, confirmam a possibilidade da existência de uma estrutura dinuclear ligada em ponte.

A análise por espectroscopia na região do infravermelho das bandas do ligante e seus complexos metálicos mostram um deslocamento negativo (negative shift) na banda referente ao estiramento CN no espetro dos complexos com relação aos ligantes livres, o que indica a coordenação via átomo de nitrogênio azometínico. Isso também é confirmado pelas bandas na região de 410-440 $\mathrm{cm}^{-1}$, referentes à ligação $\mathrm{Cu}-\mathrm{N}$. Uma banda observada em $1132 \mathrm{~cm}^{-1}$ é referente à ligação $\mathrm{N}-\mathrm{N}$ da semicarbazona.

As tiossemicarbazonas (TZs), representadas na Figura 1.3, também são classificadas como bases de Schiff e são formadas pela reação entre um aldeído ou uma cetona com uma tiossemicarbazida. Estes compostos tendem a apresentar alta deslocalização eletrônica, principalmente quando o átomo de carbono azometínico encontra-se ligado a grupos aromáticos. A presença de átomos doadores, como nitrogênio e enxofre, ajudam no potencial quelante dessas moléculas, que têm como modos de coordenação possíveis a formação de estruturas mono, bi e tridentadas, coordenadas por esses átomos doadores ou pelos átomos dos aldeídos e cetonas precursores na síntese. ${ }^{14,15}$

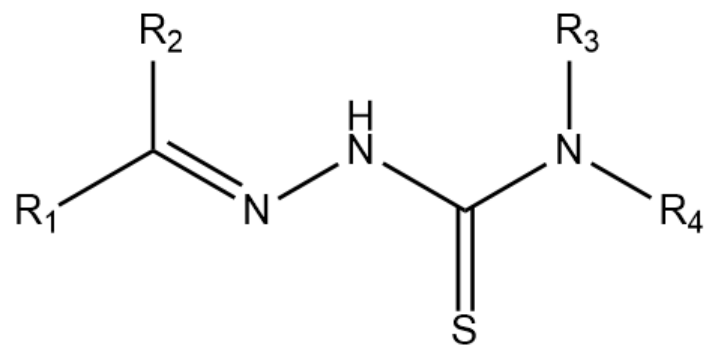

Figura 1.3. Representação da estrutura geral das tiossemicarbazonas (grupos $R=H$, grupo alquila ou arila). 
Do ponto de vista biológico, as TZs são muito utilizadas na pesquisa de novos fármacos devido a seu amplo potencial farmacológico e espectro de ação, em aplicações como agentes antitumorais, antibacterianos, antivirais, antimaláricos, antimicrobianos, antiparasitários e antituberculose. $^{16-21}$

A atividade biológica mais estudada para esses compostos é sua capacidade antitumoral, pela inibição da enzima nucleosídeo difosfato redutase, envolvida na biossíntese do DNA nas células. A $\alpha(N)$-heterocíclicas Triapina, por exemplo, demonstra grande avanço como agente antitumoral em ensaios clínicos e possui atividade promissora no combate de doenças hematológicas. ${ }^{22}$ Conforme visto na literatura, quando tiossemicarbazonas se coordenam a metais de transição, elas têm sua seletividade para células tumorais aumentada e efeitos colaterais diminuídos. $^{23,24}$

As TZs possuem predominantemente átomos doadores $O N S$ ou $N N S$ e por conta da sua ajustável taxa de doação eletrônica, apresentam uma diversidade estrutural e interessantes propriedades bioquímicas e medicinais. A estabilidade dos complexos metálicos formados com esses compostos está relacionada ao íon metálico, ao átomo doador do grupo funcional adicional, à posição e aos substituintes presentes na cadeia das TZs. A reação desses compostos com vários metais, como cobre(I), prata(I), ouro(I), mercúrio(II), paládio(II), platina(II), rutênio(II) e níquel(II), produzem complexos mono-, di- e tridentados, além de complexos polinucleares. ${ }^{13,25-27}$

Shao e colaboradores publicaram um estudo onde apresentam a síntese, caracterização e atividade biológica de compostos contendo TZs derivadas do (Z)-2-(amino(piridina-2il)metileno)-N-metilhidrazinocarbotioamida (HAm4M) complexadas com centro metálicos $\mathrm{Cu}$ (II) e $\mathrm{Zn}(\mathrm{II})$, representados na Figura 1.4. 
(a)

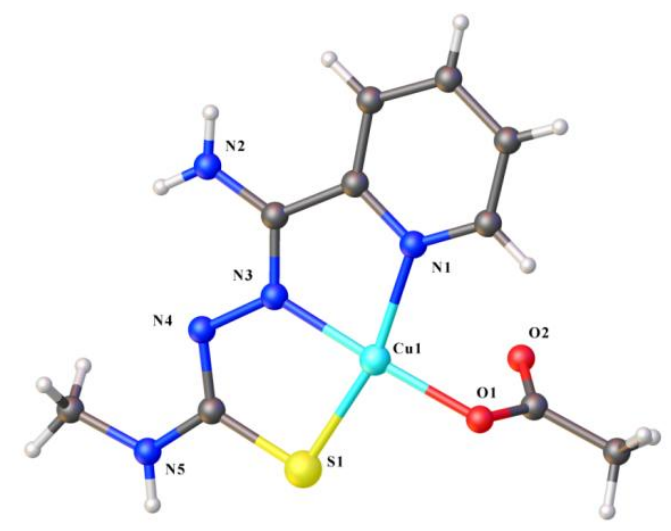

(b)

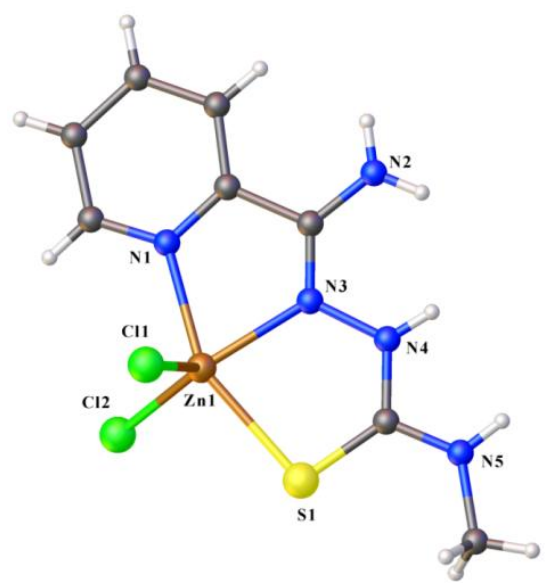

Figura 1.4. Representação das estruturas cristalinas dos complexos (a) $[\mathrm{Cu}(\mathrm{Am} 4 \mathrm{M})(\mathrm{OAc})]$ e (b) $\left[\mathrm{Zn}(\mathrm{HAm} 4 \mathrm{M}) \mathrm{Cl}_{2}\right] .{ }^{28}$

Pela análise das estruturas cristalinas e moleculares por difração de raios X dos complexos acima, observa-se que os mesmos cristalizam nos sistemas cristalinos, monoclínico e triclínico, nos grupos espaciais $\mathrm{P} 2{ }_{1} / c$ e $\mathrm{P} \overline{1}$, respectivamente.

$\mathrm{Na}$ unidade assimétrica de $[\mathrm{Cu}(\mathrm{Am} 4 \mathrm{M})(\mathrm{OAc})]$, o centro metálico está na forma tetracoordenada ligado aos átomos NNS da tiossemicarbazona e a um íon acetato, tendo geometria quadrado planar. No complexo $\left[\mathrm{Zn}(\mathrm{HAm} 4 \mathrm{M}) \mathrm{Cl}_{2}\right.$ ] pode-se observar que o átomo de $\mathrm{Zn}$ encontrase pentacoordenado, através de uma molécula do ligante HAm4M e a dois íons cloretos. O ligante HAm4M encontra-se coordenado de forma tridentada através de seus átomos de N-piridínico, Nazometínico e enxofre. O complexo possui a geometria pirâmide quadrada distorcida.

Os complexos apresentam grupos lábeis, como acetato e cloreto, o que aumentam a possibilidade de interação com biomoléculas. Foi analisada a atividade antitumoral desses 
compostos em célula tumorais de diversas linhagens, como HeLa, HepG-2 e SGC-7901, onde verificou-se que o composto de cobre apresenta citotoxicidade elevada em baixas dosagens e alta seletividade em relação a células humanas normais. Neste estudo também é apresentado a interação dos compostos contendo TZs com o DNA, onde se observa a efetividade cinética destes compostos no meio intracelular, indicando assim uma alta eficiência como agente antitumoral e baixa toxicidade. $^{28}$

A vitamina K3, menadiona (2-metil-1,4-naftoquinona), é um membro sintético lipossolúvel do grupo da vitamina $\mathrm{K}$, sua estrutura encontra-se representada na Figura 1.5. A menadiona é precursora na obtenção de bases de Schiff, além de apresentar derivados solúveis em água e diversas atividades biológicas. É muito utilizada no tratamento de diversos tipos de câncer, além de atuar como inibidora da influenza e da varíola, como também, utilizada em pesticidas e fungicidas. ${ }^{29-35}$ Quando estes ligantes se coordenam a centros metálicos suas atividades biológicas se mostram ainda mais pronunciadas. ${ }^{36}$

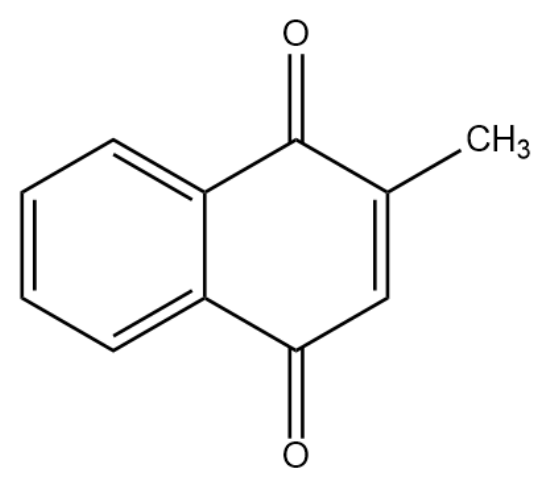

Figura 1.5. Representação da estrutura molecular da vitamina K3 (menadiona).

Casas e colaboradores ${ }^{37}$ publicaram acerca da caracterização estrutural e atividade antitumoral de um complexo de ouro(I) com um ligante tiossemicarbazona derivado da menadiona bisulfito de sódio, [AuPEt $\left.3\left(\mathrm{~K}_{3} \mathrm{tsc}\right)\right]$, representado na Figura 1.6.

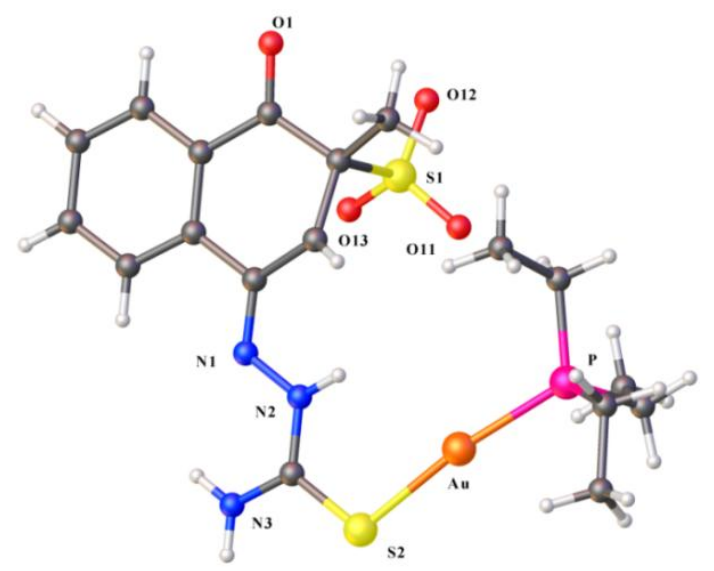

Figura 1.6. Representação da estrutura cristalina e molecular do composto $\left[\mathrm{AuPEt}_{3}\left(\mathrm{~K}_{3} \mathrm{tsc}\right)\right] .^{37}$ 
Este composto cristaliza no sistema cristalino triclínico e grupo espacial $\mathrm{P} \overline{1} 1$. O átomo de $\mathrm{Au}(\mathrm{I})$ encontra-se coordenado a um átomo de enxofre do ligante $\mathrm{K}_{3} \mathrm{tsc}^{-}$e ao átomo de fósforo da fosfina, apresentando geometria linear distorcida.

O potencial biológico do ligante derivado da vitamina K3 e do complexo de $\mathrm{Au}(\mathrm{I})$, foi testado frente a linhagem de células tumorais A2780 e A2780cis, resistentes ao medicamento cisplatina. Os resultados obtidos mostram que o ligante em sua forma livre é inativo contra as células analisadas, enquanto o complexo obteve atividade superior até a do medicamento supracitado, o que indica que o centro metálico proporciona a formação de um complexo neutro e melhora o transporte do ligante com bioativo no meio intracelular para que o mesmo possa atingir seu alvo. ${ }^{37}$

A química de coordenação do cobre(II) é muito estudada, apresentando a formação de diversos poliedros coordenativos. Usualmente com número de coordenação entre 4 a 6 , o $\mathrm{Cu}$ (II) forma compostos com geometria quadrado planar, tetraédrica, pirâmide de base quadrada, bipirâmidal trigonal ou octaédrica. O interesse em compostos de cobre ocorre devido sua acessibilidade, disponibilidade e baixo custo, bem como, o fato deles serem opções promissoras para o tratamento do câncer. ${ }^{38}$

Estudos de complexos de cobre(II) com TZ e SZ derivados do piridoxal estão sendo desenvolvidos para diversas aplicações farmacológicas. Ferrari e colaboradores ${ }^{38-40}$ publicaram, na década de 90, sobre uma grande variedade destes compostos. Como exemplo, a síntese e caracterização do composto de $\mathrm{Cu}$ (II) com piridoxal-tiossemicarbazonas (pltsc), representado na Figura 1.7. Observa-se nesse estudo, que o átomo de cobre(II) encontra-se pentacoordenado, através dos átomos $\mathrm{O}$-fenólico, $\mathrm{N}$-imínico e $\mathrm{S}$ do ligante pltsc, além de duas moléculas de água que completam o poliedro de coordenação na forma de uma pirâmide de base quadrada distorcida. Interessantemente, observa-se a formação de ligações hidrogênio intermoleculares entre o íon sulfato e o agente complexante e entre as moléculas de água presentes na estrutura cristalina. 


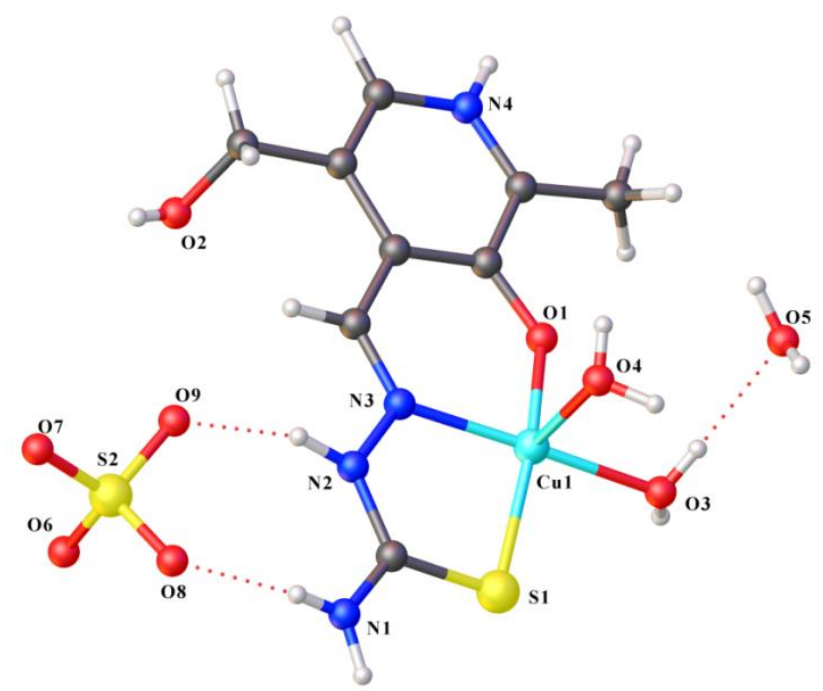

Figura 1.7. Projeção estrutural do composto $\left[\mathrm{Cu}(\mathrm{pltsc})\left(\mathrm{H}_{2} \mathrm{O}\right)_{2}\right] \mathrm{SO}_{4}{ }^{39}$

Este composto cristaliza no sistema triclínico e grupo espacial $\mathrm{P} \overline{1}$, apresentando duas moléculas em sua unidade assimétrica. Observa-se a variação nos comprimentos de ligação entre $\mathrm{Cu}-\mathrm{O}$, de 1,888 $\AA$ p para Cu-O(1), 1,994 Á para Cu-O(3) e 2,262 ̊́ para Cu-O(4), que ocorre devido a forma de zwitterion do piridoxal, ocasionada pela carga negativa no oxigênio desprotonado do grupo fenólico e que explica o encurtamento dessa ligação.

A atividade biológica deste composto foi avaliada e observou-se que não houve uma eficiência efetiva em testes antivirais e antitumorais devido a sua conformação estável, não atuando como esperado no DNA das células estudadas.

Com o intuito de otimizar a atividade biológica desta classe de compostos, o mesmo grupo de pesquisa sintetizou uma série de novos compostos de $\mathrm{Cu}$ (II) com ligantes análogos, que também foram analisados. ${ }^{40}$ Houve a formação de complexos dinucleares com a incorporação dos grupos N1,N1-dimetiltiossemicarbazonas $\left(\mathrm{Me}_{2} \mathrm{tsc} 1\right)$, N1,N2-dimetiltiossemicarbazonas $\left(\mathrm{Me}_{2} \mathrm{tsc} 2\right)$ e N1-etiltiossemicarbazonas (Ettsc) ao piridoxal, como representados nas Figuras 1.8 e 1.9. 
(a)

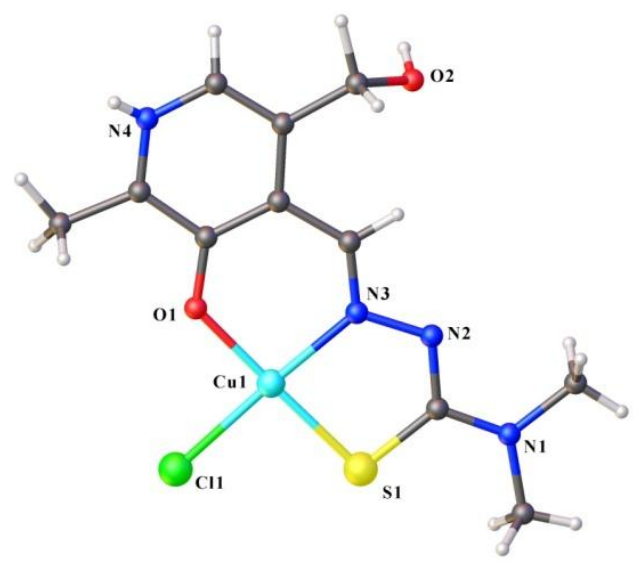

(b)

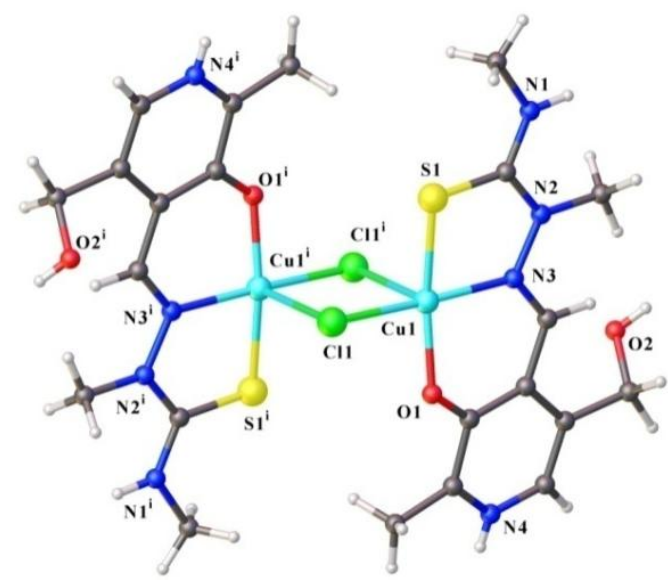

Figura 1.8. Representação da estrutura cristalina dos complexos $(\mathbf{a})\left[\mathrm{Cu}\left(\mathrm{Me}_{2} \mathrm{tsc} 1\right) \mathrm{Cl}\right]$ e (b) $\left[\mathrm{Cu}\left(\mathrm{Me}_{2} \mathrm{tsc} 2\right) \mathrm{Cl}_{2}{ }_{2}{ }^{40}\right.$

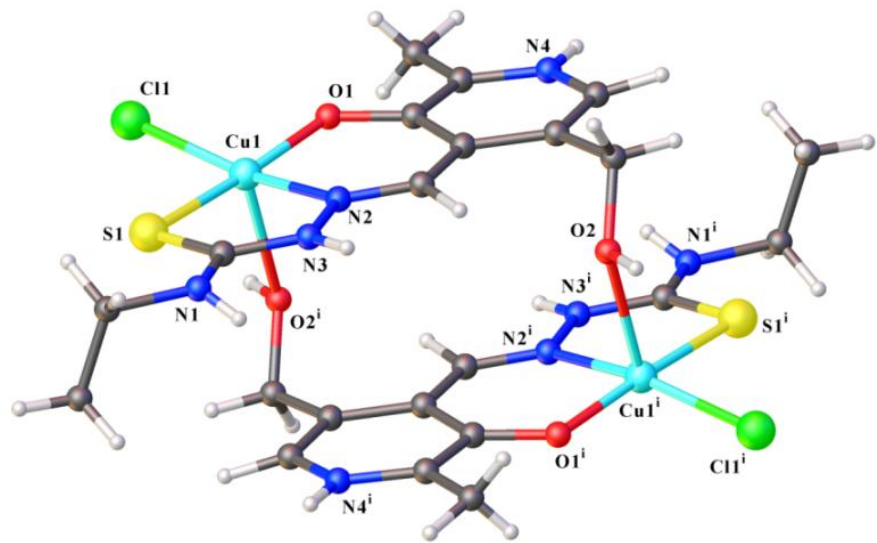

Figura 1.9. Projeção da estrutura cristalina do composto $\left[\mathrm{Cu}(\mathrm{Ettsc}) \mathrm{Cl}_{2} \mathrm{Cl}_{2}{ }^{40}{ }^{4}\right.$ Ions $\mathrm{Cl}^{-}$omitidos da figura por motivo de clareza.

Por meio de análises cristalográficas, foi possível observar que o complexo $\left[\mathrm{Cu}\left(\mathrm{Me}_{2} \mathrm{tsc} 1\right) \mathrm{Cl}\right]$ cristalizou no sistema cristalino triclínico e grupo espacial $\mathrm{P} \overline{1}$. O centro metálico apresenta geometria quadrado planar e há uma fraca interação entre o átomo de cobre e os átomos 
de carbono do anel benzênico. As ligações hidrogênio no grupo fenólico com o íon cloreto completam a formação da unidade assimétrica. No complexo $\left[\mathrm{Cu}\left(\mathrm{Me}_{2} 2 \mathrm{tsc} 2\right) \mathrm{Cl}\right]_{2}$ observa-se a cristalização também com grupo espacial P $\overline{1}$ e o centro metálico com geometria pirâmide de base quadrada, onde compõem a esfera de coordenação o ligante tridentado NOS e o íon cloreto atua em ponte entre os dois átomos de cobre na formação de um dímero. $\mathrm{O}$ complexo $\left[\mathrm{Cu}(\mathrm{Ettsc}) \mathrm{Cl}_{2}\right]_{2} \mathrm{Cl}_{2}$ cristaliza no sistema cristalino monoclínico e grupo espacial $\mathrm{P}{ }_{1} / c$, com geometria pirâmide de base quadrada. Também se observa a formação de um dímero através da ligação do grupo $\mathrm{OH}$ com o centro metálico.

Complexos de zinco com ligantes bases de Schiff também vêm sendo muito estudados. Em 2003, Kasuga e colaboradores ${ }^{41}$ publicaram a síntese, caracterização estrutural e atividade antimicrobiana de 12 complexos de zinco(II) com 6 ligantes distintos (4 tiossemicarbazonas e 2 semicarbazonas). Dois desses complexos, $\left[\mathrm{Zn}(\mathrm{Hasc})_{2}\right]\left(\mathrm{NO}_{3}\right)$ e $\left[\mathrm{ZnCl}_{2}(\mathrm{Hasc})\right]$, foram sintetizados a partir do ligante tridentado semicarbazona (Hasc), estão representados na Figura 1.10. 
(a)

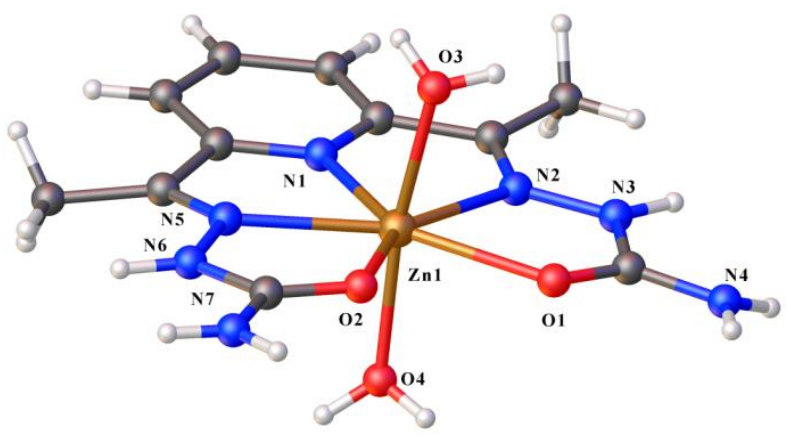

(b)

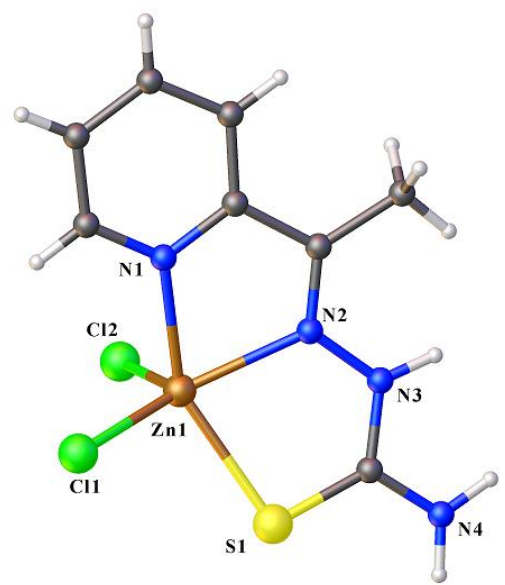

Figura 1.10. Representação da estrutura dos complexos (a) $\left[\mathrm{Zn}(\mathrm{Hasc})_{2}\right]\left(\mathrm{NO}_{3}\right)$ (íons nitrato omitido da figura por motivo de clareza) e (b) $\left[\mathrm{ZnCl}_{2}(\mathrm{Hasc})\right]^{41}$

$\mathrm{Na}$ estrutura do composto $\left[\mathrm{Zn}(\mathrm{Hasc})_{2}\right]\left(\mathrm{NO}_{3}\right)$, o átomo de $\mathrm{Zn}(\mathrm{II})$ encontra-se coordenado a uma semicarbazona pentadentada. Duas posições do poliedro de coordenação na forma de uma bipirâmide pentagonal são ocupadas porduas moléculas de água. Os comprimentos das ligações O1-C8, N3-C8 e N2-C6, bem como, o caráter planar do C6=N2-N3=C8-N4 indicam uma deslocalização eletrônica nessa molécula.

No complexo [ $\mathrm{ZnCl}_{2}$ (Hasc)], observa-se a semicarbazona e dois íons $\mathrm{Cl}^{-}$vindos do $\mathrm{ZnCl}_{2}$ se coordenando ao átomo de $\mathrm{Zn}$ (II) que se encontra pentacoordenado com uma geometria pirâmide de base quadrada. 


\section{OBJETIVOS}




\section{Objetivos}

O presente Trabalho de Conclusão de Curso objetiva a síntese e caracterização estrutural, através da técnica de difração de raios $\mathrm{X}$ de monocristal de compostos inéditos derivados da vitamina K3, além de diversas tentativas de síntese e caracterização de seus complexos com metais tais como Zinco, Cobre, Ouro, entre outros, visando a obtenção de compostos que posteriormente serão explorados quanto as suas aplicações farmacológicas.

Sendo assim, têm-se os seguintes objetivos específicos:

- Sintetizar ligantes do tipo semicarbazonas e tiossemicarbazonas inéditos derivados da vitamina $\mathrm{K} 3$;

- Realizar reações de complexação com os ligantes obtidos e os íons metálicos $\mathrm{Cu}(\mathrm{II})$ e $\mathrm{Zn}(\mathrm{II})$;

- Elucidar as estruturas cristalinas e moleculares dos compostos obtidos utilizando a técnica de difração de raios $\mathrm{X}$ de monocristal;

- Complementar a caracterização estrutural dos produtos obtidos por meio de técnicas espectroscópicas, análise elementar e ponto de fusão;

- Analisar as possíveis interações existentes nos compostos sintetizados através do estudo das superfícies de Hirshfeld. 
3. MATERIAIS E MÉTODOS 


\section{Materiais e Métodos}

\subsection{Reagentes e Solventes}

Os reagentes utilizados na síntese dos ligantes foram: menadiona - $\left(\mathrm{C}_{11} \mathrm{H}_{8} \mathrm{O}_{2}\right)$, menadiona bisulfito de sódio - $\left(\mathrm{C}_{11} \mathrm{H}_{9} \mathrm{O}_{2} \mathrm{SO}_{3} \mathrm{Na}\right)$ (representados na Figura 3.1), 4-feniltiossemicarbazida $\left(\mathrm{C}_{7} \mathrm{H}_{9} \mathrm{~N}_{3} \mathrm{~S}\right)$, tiossemicarbazida $-\left(\mathrm{CH}_{5} \mathrm{~N}_{3} \mathrm{O}\right)$, semicarbazida hidroclorada $-\left(\mathrm{CH}_{5} \mathrm{~N}_{3} \mathrm{O} \cdot \mathrm{HCl}\right)$, e fenilsemicarbazida $-\left(\mathrm{C}_{7} \mathrm{H}_{9} \mathrm{ON}_{3}\right)$.

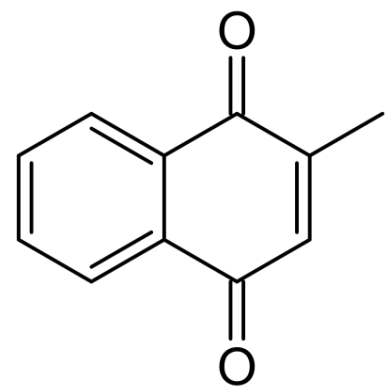

Figura 3.1. Estrutura da menadiona.

Todos os reagentes foram adquiridos comercialmente da empresa Sigma-Aldrich, assim como, os sais dos metais utilizados na preparação dos complexos, como: $\mathrm{CuBr}_{2}, \mathrm{CuCl}_{2}, \mathrm{Cu}(\mathrm{Ac})_{2}$, $\mathrm{ZnCl}_{2}, \mathrm{ZnBr}_{2}$ e $\mathrm{Zn}(\mathrm{Ac})_{2}$

Os solventes usados na síntese dos ligantes e dos complexos, nas recristalizações e nas análises por espectroscopia eletrônica foram obtidos pela Vetec, e são: Metanol $-\mathrm{CH}_{3} \mathrm{OH}$, Etanol 95\% - $\mathrm{CH}_{3} \mathrm{CH}_{2} \mathrm{OH}, \mathrm{N}, \mathrm{N}$-dimetilformamida $-\left(\mathrm{CH}_{3}\right)_{2} \mathrm{NCOH}(\mathrm{DMF})$, Acetonitrila $-\mathrm{CH}_{3} \mathrm{CN}$, Trietilamina $-\mathrm{C}_{6} \mathrm{H}_{15} \mathrm{~N}$, Tetrametilsilano $-\mathrm{C}_{4} \mathrm{H}_{12} \mathrm{Si}$ e Dimetilsulfóxido deuterado $-\mathrm{C}_{2} \mathrm{D}_{6} \mathrm{OS}$.

\subsection{Síntese Geral dos ligantes}

As sínteses, tanto dos complexos quanto dos ligantes, foram realizadas sob refluxo, a uma temperatura média de $150^{\circ} \mathrm{C}$ ou a temperatura ambiente, dependendo da reação.

Para a síntese dos ligantes foram realizadas reações utilizando-se $1 \mathrm{mmol}$ da base de Schiff e $1 \mathrm{mmol}$ da menadiona ou da menadiona bisulfito de sódio, em etanol. Algumas gotas de ácido sulfúrico foram adicionadas para que a formação do ligante se dê por catálise ácida, conforme representação na Figura 3.2.

\subsubsection{Síntese do ligante menadiona fenil-semicarbazona (K3Phsz)}

Inicialmente, foram solubilizados em um balão de fundo redondo $2 \mathrm{mmol}(344,4 \mathrm{mg})$ de menadiona em $5 \mathrm{~mL}$ de etanol 95\%, logo em seguida foram adicionados $2 \mathrm{mmol}(375,2 \mathrm{mg}) \mathrm{de}$ 
fenil-semicarbazida, solubilizadas na mesma quantidade de solvente. A reação foi feita sob as condições de refluxo por $3 \mathrm{~h}$. O produto cristalino foi obtido a partir da evaporação lenta da solução mãe e posterior recristalização direta.<smiles>CC1=CC(=O)c2ccccc2C1=O</smiles>

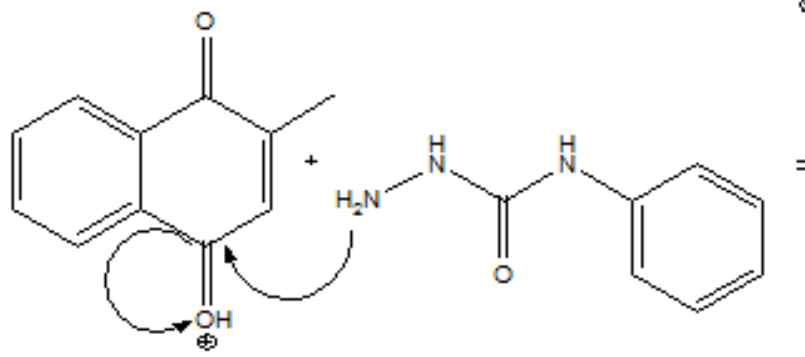

(2)<smiles>CNNC1(O)C=C(C)C(=O)c2ccccc21</smiles><smiles>CC1=CC(O)([NH2+]NC(=O)Nc2ccccc2)c2ccccc2C1=O</smiles><smiles></smiles><smiles>CC1=CC(=NNC(=O)Nc2ccccc2)c2ccccc2C1=O</smiles>

Figura 3.2. Esquema mecanístico da formação do ligante K3Phsz. 


\subsection{Síntese Geral dos Complexos}

De maneira geral, para a síntese dos complexos, foram utilizados 0,1 mmol do ligante e 0,1 mmol do sal do metal, realizadas em metanol ou acetonitrila. Para os acetatos foi utilizada uma proporção de 2:1. Algumas gotas de trietilamina foram adicionadas para desprotonar o ligante, quando necessário. Os produtos foram recristalizados em $\mathrm{N}, \mathrm{N}$-dimetilformamida por recristalização direta.

\subsection{Caracterização dos compostos obtidos}

\subsubsection{Difração de Raios $X$ de Monocristal}

A determinação das estruturas cristalinas e moleculares dos compostos obtidos foi realizada a partir do método de difração de raios $\mathrm{X}$ de monocristal, utilizando um difratômetro SMART APEX II CCD (Charge Coupled Device Detector Bruker) com monocromador de grafite e que possui fonte de radiação de Mo-K $\alpha(0,71073 \AA$ A ) a aproximadamente $296 \mathrm{~K}$, pertencente ao Instituto de Química da Universidade de Brasília (IQ-UnB). As informações da coleta de dados e refinamento das estruturas cristalinas dos compostos são apresentadas nas Tabelas 4.1.

\subsubsection{Superfície de Hirshfeld}

A superfície de Hirshfeld (HS) ${ }^{42,43}$, foi gerada utilizando o CrystalExplorer 17.5. ${ }^{44} \mathrm{O}$ arquivo na extensão Crystallographic Information File (CIF), obtido pela Difratometria de Raios $\mathrm{X}$ de Monocristal, foi usado como base. As superfícies 3D $d_{\text {norm }}$ (distância de contato normalizada) foram mapeadas em uma escala fixa de cor, que vai de -0.5 (vermelho) a 1.4(azul). A propriedade $d_{\text {norm}}$, definida pela Equação (1), é a soma de duas quantias, $d_{i}$ e $d_{e}$, normalizadas pelo Raio de van der Waals dos átomos envolvidos. $d_{i}$ é a distância interna mais próxima de um dado ponto da superfície, enquanto $d_{e}$ é o contato externo mais próximo. O shape index $S_{\text {range }}$ de -1.0 a 1.0 para o composto é definido pela Equação (2).

$$
\begin{aligned}
& \mathrm{d}_{\text {norm }}=\frac{\mathrm{d}_{\mathrm{i}}-\mathrm{r}_{\mathrm{i}}^{\mathrm{vdW}}}{\mathrm{r}_{\mathrm{i}}^{\mathrm{vdW}}}+\frac{\mathrm{d}_{\mathrm{e}}-\mathrm{r}_{\mathrm{e}}^{\mathrm{vdW}}}{\mathrm{r}_{\mathrm{e}}^{\mathrm{vdW}}}(1) \\
& \mathrm{S}=\frac{-2}{\pi} \tan ^{-1} \frac{\mathrm{K}_{1}+\mathrm{K}_{2}}{\mathrm{~K}_{1}-\mathrm{K}_{2}}
\end{aligned}
$$




\subsubsection{Espectroscopia Vibracional na Região do Infravermelho}

Os espectros vibracionais na região do infravermelho foram obtidos em um espectrofotômetro FT-IR Varian 640 na região de 4000-400 cm-1 , pertencente ao IQ-UnB, utilizando pastilhas de brometo de potássio $(\mathrm{KBr})$ preparadas na proporção aproximada de $10 \mathrm{mg}$ de composto para $180 \mathrm{mg}$ de $\mathrm{KBr}$.

\subsubsection{Espectroscopia na Região do Ultravioleta-Visível}

Os espectros de absorção molecular na região do ultravioleta-visível dos ligantes e dos complexos foram obtidos em um espectrofotômetro Agilent HP 8453, utilizando soluções com concentrações de aproximadamente $2 \times 10^{-5}$ mol. $\mathrm{L}^{-1}$ e $1 \times 10^{-3}$ mol. $\mathrm{L}^{-1}$, preparadas nos solventes metanol e N,N-dimetilformamida. Esse espectrofotômetro também pertence ao IQ-UnB.

\subsubsection{Ressonância Magnética Nuclear (RMN)}

Para maior elucidação acerca da estrutura do composto obtido, foi feita uma análise do mesmo por RMN de ${ }^{1} \mathrm{H}$ em um espectrômetro Bruker Avance III HD (600 MHz para ${ }^{1} \mathrm{H}$ ), utilizando dimetilsulfóxido deuterado $\left(\mathrm{DMSO}-\mathrm{d}_{6}\right.$ ) como solvente e tetrametilsilano (TMS) como referência interna. Esse equipamento utilizado encontram-se presente no IQ-UnB.

\subsubsection{Análise Elementar CHN}

Os teores de carbono, nitrogênio e hidrogênio dos complexos sintetizados foram determinados em um equipamento Perkin Elmer/Series II 2400 analyzer, pertencente ao Instituto de Química da Universidade de Brasília, que utiliza um padrão de acetanilida.

\subsubsection{Ponto de Fusão (p.f.)}

A determinação dos pontos de fusão dos complexos metálicos e dos ligantes foi realizada em um aparelho digital MQAPF-302 da Micro Química, pertencente ao laboratório LASIC da UnB. 
4. RESULTADOS E DISCUSSÃO 


\section{Resultados e Discussão}

Nesta parte do trabalho são apresentados e analisados os resultados obtidos pelas técnicas de difração de raios $\mathrm{X}$ de monocristal, espectroscopia na região do infravermelho, espectroscopia na região do ultravioleta-visível, ressonância magnética nuclear de ${ }^{1} \mathrm{H} \mathrm{e}{ }^{13} \mathrm{C}$, análise elementar de CHN e ponto de fusão do composto inédito obtido, a menadiona fenil-semicarbazona (K3Phsz). Serão analisados também os estudos teóricos de superfície de Hirshfeld.

\section{1 . Rendimento, Ponto de Fusão e Análise Elementar}

Na Tabela 4.1 estão dispostos os dado referentes ao ligante sintetizado, pode-se observar que o composto apresenta elevado rendimento e também um bom grau de pureza.

Tabela 4.1. Dados de ponto de fusão, rendimento e análise elementar de K3Phsz.

\begin{tabular}{lcccc}
\hline Ligante & $\begin{array}{c}\text { Ponto de } \\
\text { fusão }\left({ }^{\mathbf{0}} \mathbf{C}\right)\end{array}$ & Rendimento & $\begin{array}{c}\text { Análise Elementar } \\
\text { Teórica }(\%)\end{array}$ & $\begin{array}{c}\text { Análise Elementar } \\
\text { Experimental (\%) }\end{array}$ \\
\hline K3Phsz & 230 & $80-85 \%$ & $\mathrm{C}(70,81), \mathrm{H}(4,95)$, & $\mathrm{C}(70,21), \mathrm{H}(5,02)$, \\
& & & $\mathrm{N}(13,76)$ & $\mathrm{N}(11,22)$ \\
\hline
\end{tabular}

\subsection{Análise Estrutural de K3Phsz}

Os dados obtidos da coleta de intensidades e refinamento indicam que o composto K3Phsz cristaliza no sistema cristalino $\mathrm{P} 2{ }_{1} / \mathrm{n}$ e grupo espacial monoclínico. A Figura 4.1 apresenta a projeção ORTEP do ligante com a numeração de todos os átomos não hidrogenóides e a Tabela 4.2 apresenta os dados da coleta de intensidades e do refinamento da estrutura cristalina e molecular do mesmo. 


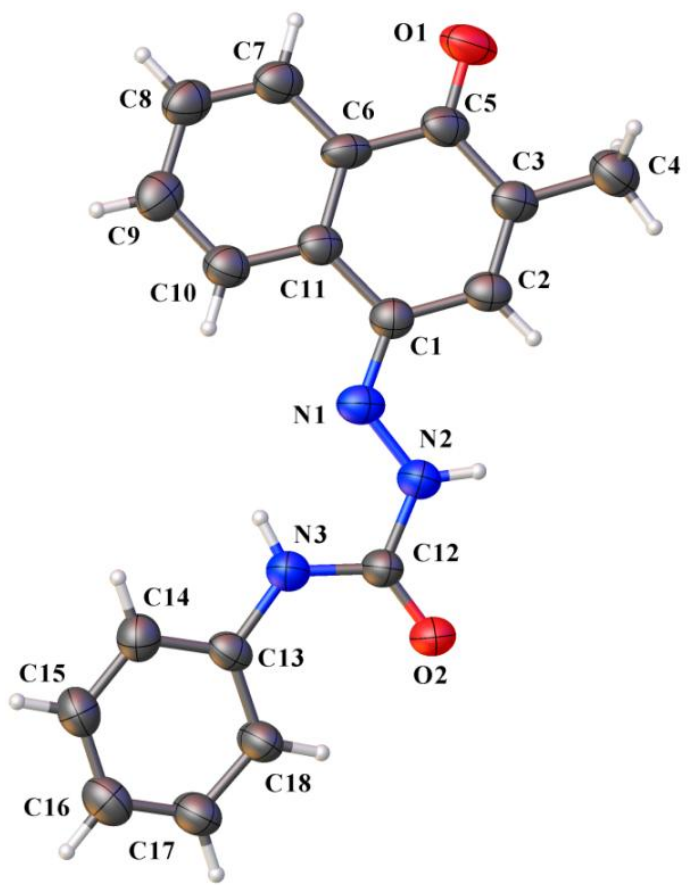

Figura 4.1. Representação estrutural do ligante K3phsz. Elipsóides térmicos representados a um nível de $30 \%$ de probabilidade.

Tabela 4.2. Dados da coleta de intensidades e do refinamento da estrutura cristalina e molecular do composto K3Phsz.

\begin{tabular}{|c|c|}
\hline Fórmula molecular & $\mathrm{C}_{18} \mathrm{H}_{15} \mathrm{~N}_{3} \mathrm{O}_{2}$ \\
\hline Massa molecular $\left(\mathrm{g} \mathrm{mol}^{-1}\right)$ & 305,33 \\
\hline Sistema cristalino & Monoclínico \\
\hline Grupo espacial & $P 2_{1} / \mathrm{n}$ \\
\hline \multicolumn{2}{|l|}{ Parâmetros da cela } \\
\hline $\mathbf{a}(\AA)$ & $5,78(1)$ \\
\hline $\mathbf{b}(\AA)$ & $17,19(5)$ \\
\hline $\mathbf{c}(\AA)$ & $15,29(5)$ \\
\hline$\beta\left({ }^{\circ}\right)$ & $99,74(4)$ \\
\hline $\mathbf{V}\left(\AA^{3}\right)$ & $1498(8)$ \\
\hline $\mathbf{Z}$ & 4 \\
\hline Densidade $\left(\mathrm{mg} \mathrm{cm}^{-3}\right)$ & 1,354 \\
\hline Coeficiente linear de absorção $\mu\left(\mathrm{mm}^{-1}\right)$ & 0,091 \\
\hline \multirow[t]{3}{*}{ Índices de varredura $h, k$, l } & $-6 \leq h \leq 6$ \\
\hline & $-20 \leq \mathrm{k} \leq 20$ \\
\hline & $-18 \leq 1 \leq 18$ \\
\hline
\end{tabular}

Número de reflexões 


\begin{tabular}{ll}
\hline Coletadas & 32952 \\
Independentes & 2634 \\
Completeness $(\%)$ & 99,4 \\
Método de solução da estrutura & Métodos diretos \\
Método de refinamento & Full-matrix least-squares on $\mathrm{F}^{2}$ \\
Programa de refinamento & SHELXL-97 (Sheldrick, 2008) \\
Critério de observação & {$[\mathrm{I}>2 \sigma(\mathrm{I})]$} \\
Número de parâmetros & 210 \\
Correção de absorção & Multi-scan \\
F(000) & 640 \\
Goodness-of-fit $\left(\mathbf{F}^{2}\right)$ & 0,987 \\
Índices de discordância finais & $\mathrm{R}_{1}=0,0834 \quad \mathrm{wR}_{2}=0,1744$ \\
Densidade eletrônica residual $\left(\mathbf{e} \AA^{-3}\right)$ & $0,24 /-0,23$ \\
\hline
\end{tabular}

Estão representadas nas Figuras 4.2(a) e 4.2(b) a cela unitária do ligante K3Phsz, constituída por 4 unidades assimétricas, e a sua referência de número 14 da International Tables for Crystallography ${ }^{45}$.As duas figuras são representativas do grupo espacial $P 2{ }_{1} / \mathrm{n}$. Comparando-se as duas representações é possível observar as diferentes operações de simetria presentes, como o centro de inversão e um eixo helicoidal 21 paralelo ao eixo $b$ e perpendicular a um plano de deslizamento no plano da cela com deslocamento de $1 / 2$ na diagonal.
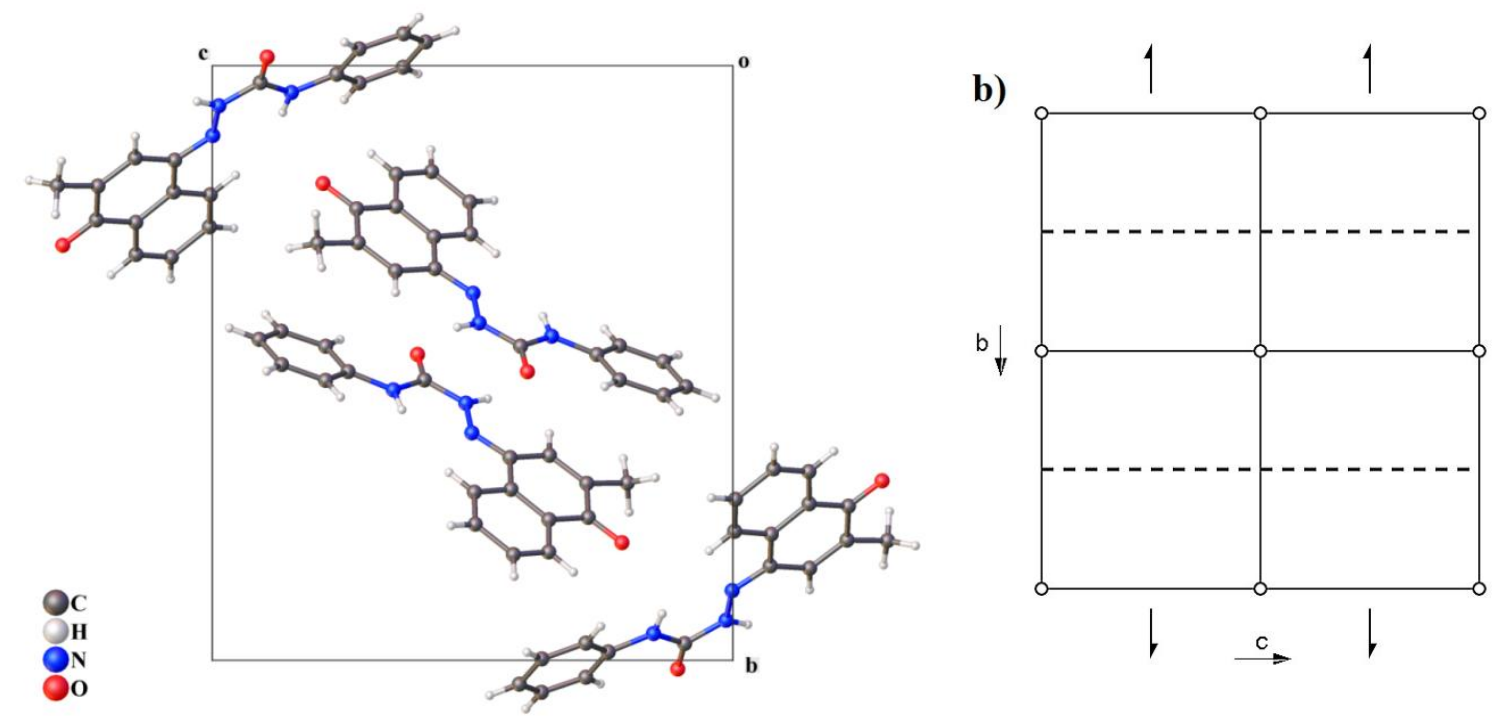

Figura 4.2. (a) Representação da cela unitária do composto K3Phsz no plano $b c$. (b) Diagrama referente ao grupo espacial $\mathrm{P}_{1} / \mathrm{n}$ da International Tables for Crystallography ${ }^{45}$ 
Os comprimentos de ligação obtidos no ligante em questão levam à confirmação de que o mesmo, quando no estado sólido, se apresenta em sua forma tautomérica cetônica, já que as

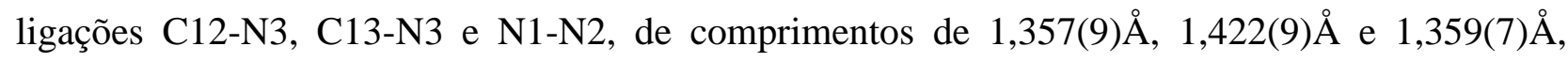
respectivamente, apresentam maior caráter de ligação simples, enquanto as ligações C12-O2, de

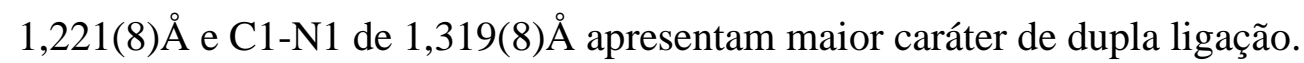

Foram observados também os ângulos das ligações C1-N1-N2, N1-N2-C12, N2C12-O2 e N2-C12-N3, todos próximos a $120^{\circ}$, o que corrobora com a planaridade esperada para essa classe de compostos. A Tabela 4.3 apresenta alguns valores de ângulos e comprimentos de ligação selecionados para o composto K3phsz.

Tabela 4.3. Comprimentos e ângulos de ligação selecionados para o composto K3Phsz.

\begin{tabular}{|cc|cc|}
\hline \multicolumn{2}{c|}{ Comprimento de Ligação $(\AA)$} & \multicolumn{2}{|c|}{ Ângulo de Ligação $\left(^{\circ}\right)$} \\
\hline C12-N3 & $1,357(9)$ & C1-N1-N2 & $121,5(6)$ \\
C13-N3 & $1,422(9)$ & N1-N2-C12 & $119,1(6)$ \\
N1-N2 & $1,359(7)$ & N2-C12-O2 & $120,2(8)$ \\
C12-O2 & $1,221(8)$ & N2-C12-N3 & $114,5(7)$ \\
C1-N1 & $1,319(8)$ & & \\
\hline
\end{tabular}

$\mathrm{Na}$ estrutura do ligante K3Phsz é possível observar a presença de interações intermoleculares do tipo ligação hidrogênio $\mathrm{C}=\mathrm{O} \cdots \mathrm{H}-\mathrm{N}$, representadas na Figura 4.3, que estabilizam sua estrutura cristalina e unem duas moléculas na formação de um dímero. 


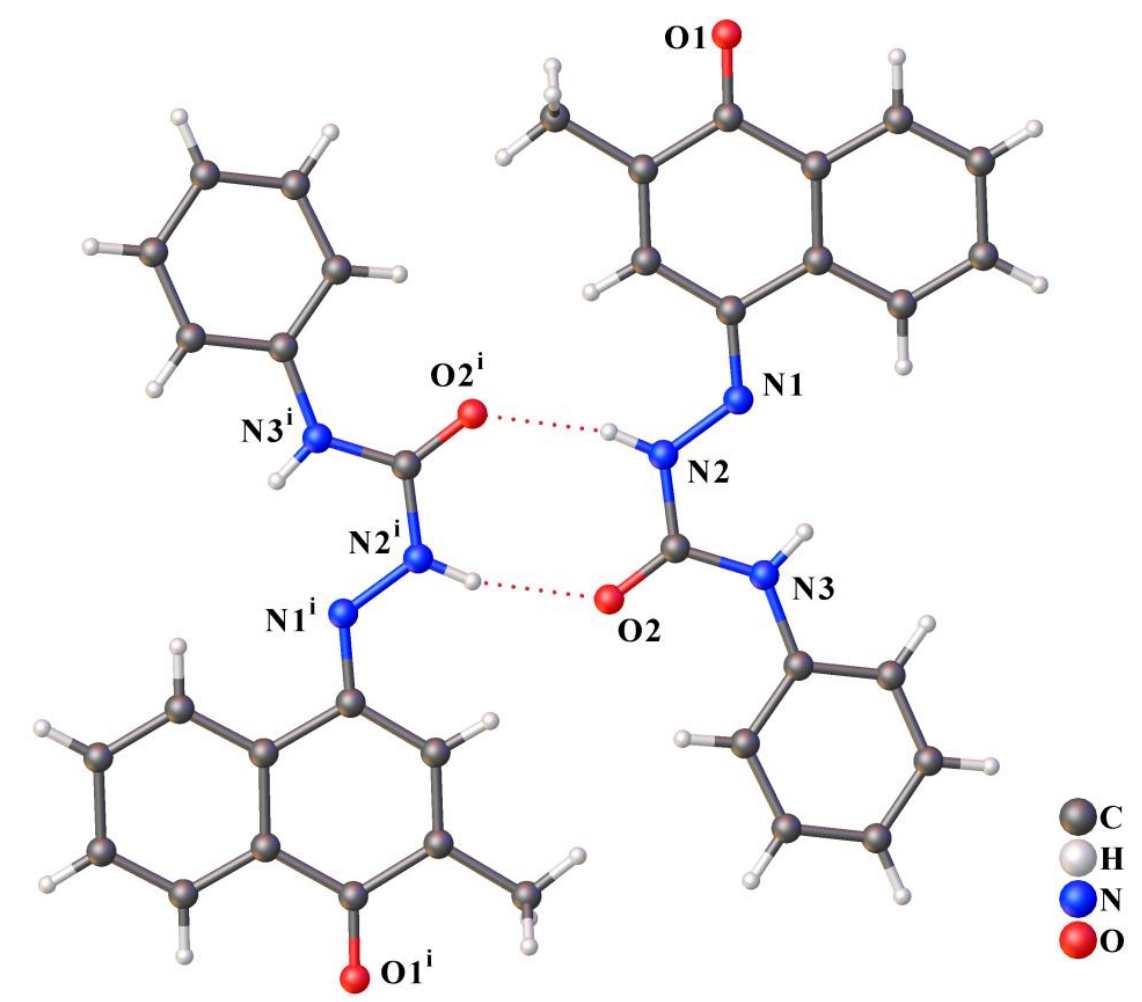

Figura 4.3. Representação das interações intermoleculares do ligante K3Phsz.

\subsection{Superfície de Hirshfeld}

A superfície de Hirshfeld (HS) é uma técnica utilizada para analisar e verificar os tipos de ligações intermoleculares em uma rede cristalina. ${ }^{42,43}$ As representações da HS do composto obtido estão nas Figuras 4.4 e 4.5. A superfície $d_{\text {norm }}$ apresenta as cores vermelho, azul e branco, e elas representam, respectivamente, distâncias de contato menores, maiores e próximas à soma dos raios de van der Waals.

Os pontos vermelhos observados na superfície $d_{n o r m}$ do composto indicam a presença de contatos próximos na estrutura cristalina como ligações de hidrogênio clássicas e não-clássicas entre as moléculas do ligante K3Phsz. Observa-se claramente que as interações mais fortes são as interações de hidrogênio que unem duas moléculas na formação do dímero. 


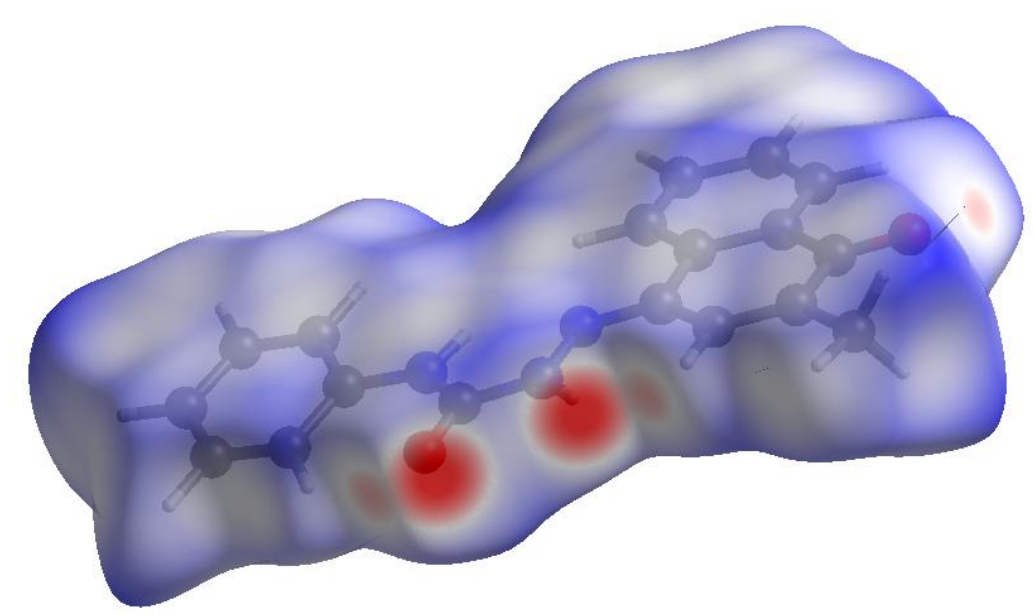

Figura 4.4. Superfície de Hirshfeld mapeada no $d_{\text {norm }}$ para o ligante K3Phsz, (vista de frente).

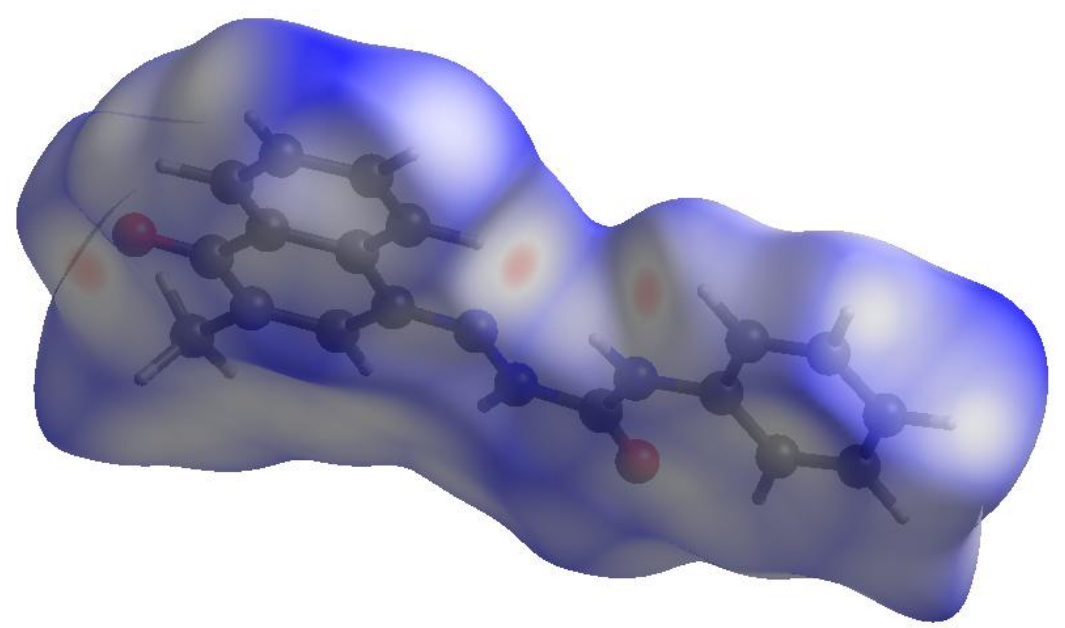

Figura 4.5. Superfície de Hirshfeld mapeada no $d_{\text {norm }}$ para o ligante K3Phsz, (vista de costas).

\subsection{Espectroscopia Vibracional na Região do Infravermelho}

O espectro vibracional na região do infravermelho médio $\left(4000-400 \mathrm{~cm}^{-1}\right)$ do ligante K3Phsz encontra-se na Figura 4.6. 


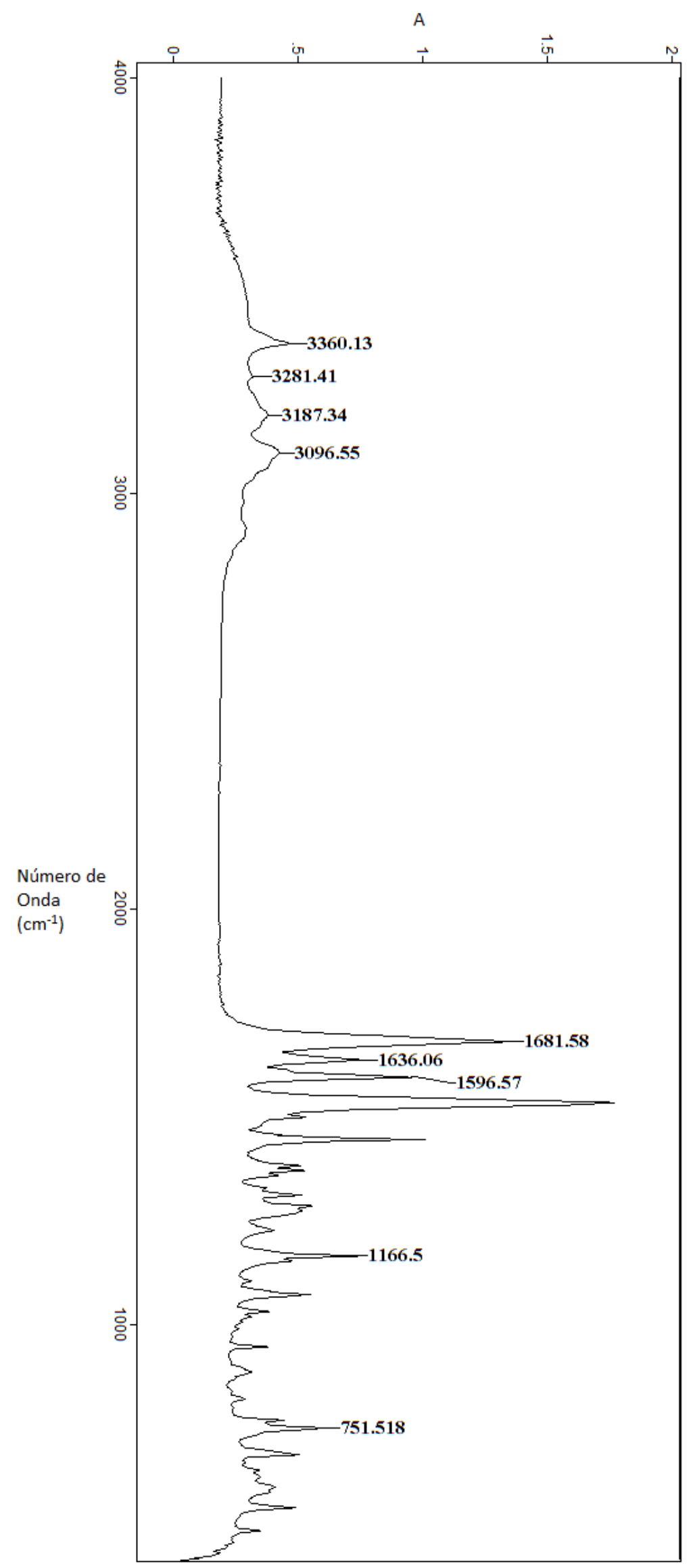

Figura 4.6. Espectro de FT-IR do ligante K3Phsz. 
$\mathrm{Na}$ Tabela 4.4 encontram-se listadas as principais bandas características para compostos da classe das semicarbazonas, assim como, algumas outras bandas relevantes encontradas no espectro do composto em questão. A banda intensa referente ao estiramento da ligação $\mathrm{C}=\mathrm{O}$ é observada em $1681,58 \mathrm{~cm}^{-1}$ e que corrobora para a confirmação da estrutura do tautômero esperado na forma cetônica.

Tabela 4.4. Frequências de estiramento, $\mathrm{em}^{-1}$, e deformação angular dos modos de vibração selecionados para o composto K3Phsz.

\begin{tabular}{|c|c|}
\hline Vibração & Número de Onda $\left(\mathrm{cm}^{-1}\right)$ \\
\hline$v(\mathrm{~N}-\mathrm{H})$ & $>3000$ \\
\hline$v\left(\mathrm{C}=\mathrm{O}_{\text {cetona }}\right)$ & 1682 \\
\hline$v\left(\mathrm{C}=\mathrm{O}_{\text {amida }}\right)$ & 1597 \\
\hline$v(\mathrm{C}=\mathrm{N})$ & 11636 \\
\hline$v(\mathrm{~N}-\mathrm{N})$ & $>3000$ \\
\hline$v\left(\mathrm{C}-\mathrm{H}_{\text {alceno }}\right)$ & 752 \\
\hline orto- & $3050-3150$ \\
\hline Anéis aromáticos & \\
\hline
\end{tabular}

\subsection{Espectroscopia na Região do Ultravioleta-Visível}

Os espectros de absorção molecular na região do ultravioleta-visível ou espectros eletrônicos do ligante K3Phsz foram determinados utilizando concentrações de $1 \times 10^{-5} \mathrm{~mol} \mathrm{~L}^{-1}$ nos solventes metanol e N,N-dimetilformamida. O objetivo de estudar os espectros eletrônicos é verificar possíveis transições eletrônicas e verificar o efeito do solvente nas bandas de absorção. Na Figura 4.7 encontram-se representados os espectros de UV-Vis para o ligante em estudo. 


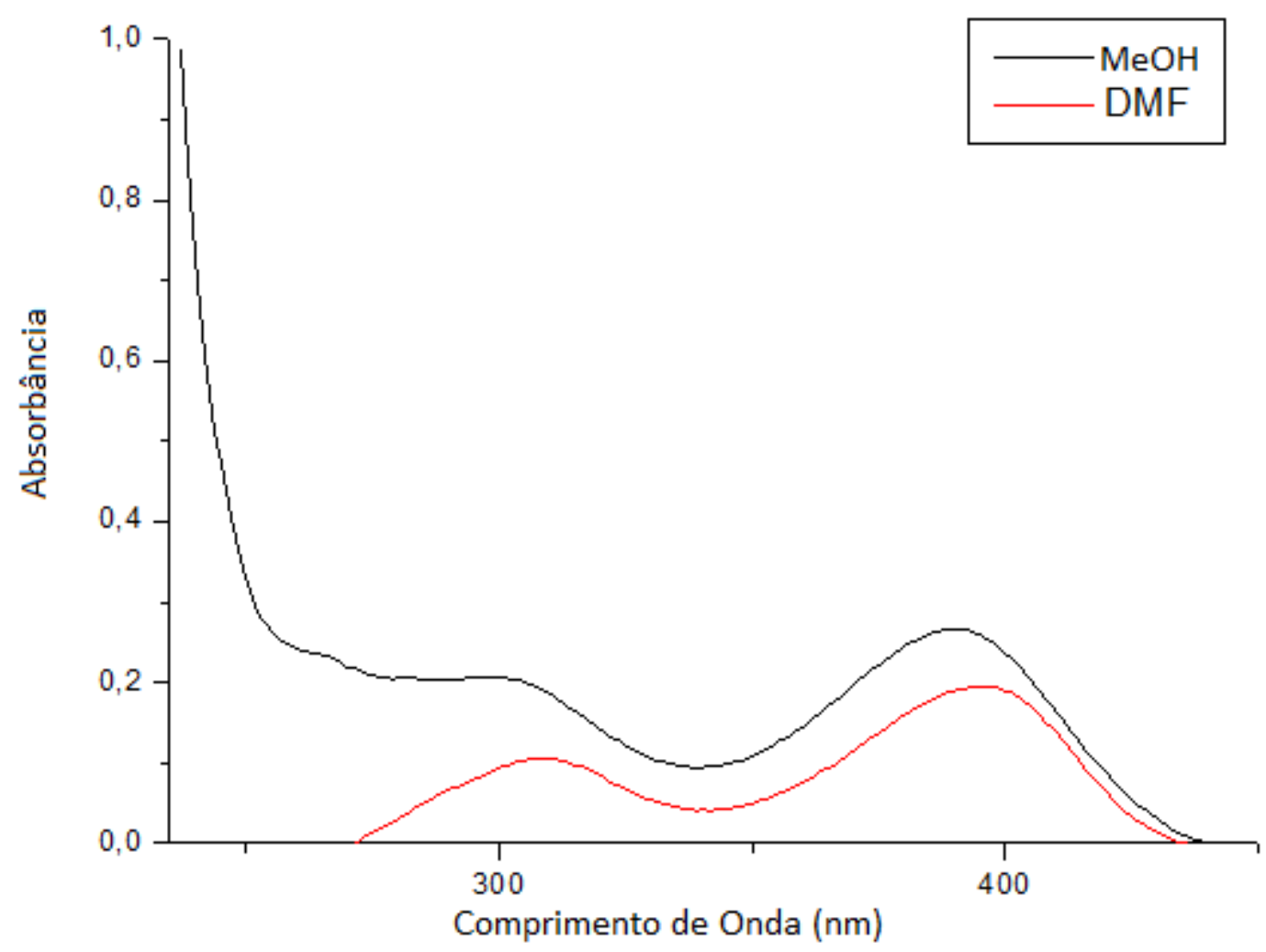

Figura 4.7. Espectro de absorção molecular na região do ultravioleta-visível para o ligante K3Phsz nos solventes $\mathrm{MeOH}$ e DMF (concentração de $1 \times 10^{-5} \mathrm{~mol} / \mathrm{L}$ ).

Foram observadas para o composto duas bandas referentes às transições eletrônicas $\pi \rightarrow \pi^{*}$, do grupo cromóforo $\mathrm{C}=\mathrm{C}$, e $\mathrm{n} \rightarrow \pi^{*}$, dos grupos cromóforos $\mathrm{C}=\mathrm{O}$, respectivamente em 301,9 $\mathrm{nm}$ e 390,3 nm em MeOH e 307,6 nm e 395,5 nm em DMF.

Em metanol, pode-se perceber que os valores de absorbância são maiores em relação ao espectro obtido em DMF, além de ocorrer um deslocamento no sentido de maiores comprimentos de onda no espectro do mesmo, e isso se deve ao fato do $\mathrm{MeOH}$, por ser um solvente polar prótico, conseguir solvatar as moléculas do agente complexante de forma mais efetiva que o outro.

\subsection{Ressonância Magnética Nuclear (RMN)}

A análise feita por ressonância magnética nuclear de ${ }^{1} \mathrm{H}$ também dá indícios de que, de fato, o composto se apresenta na forma esperada. O espectro obtido para a ressonância magnética nuclear de ${ }^{1} \mathrm{H}$ da molécula do K3Phsz se encontra na Figura 4.8. 


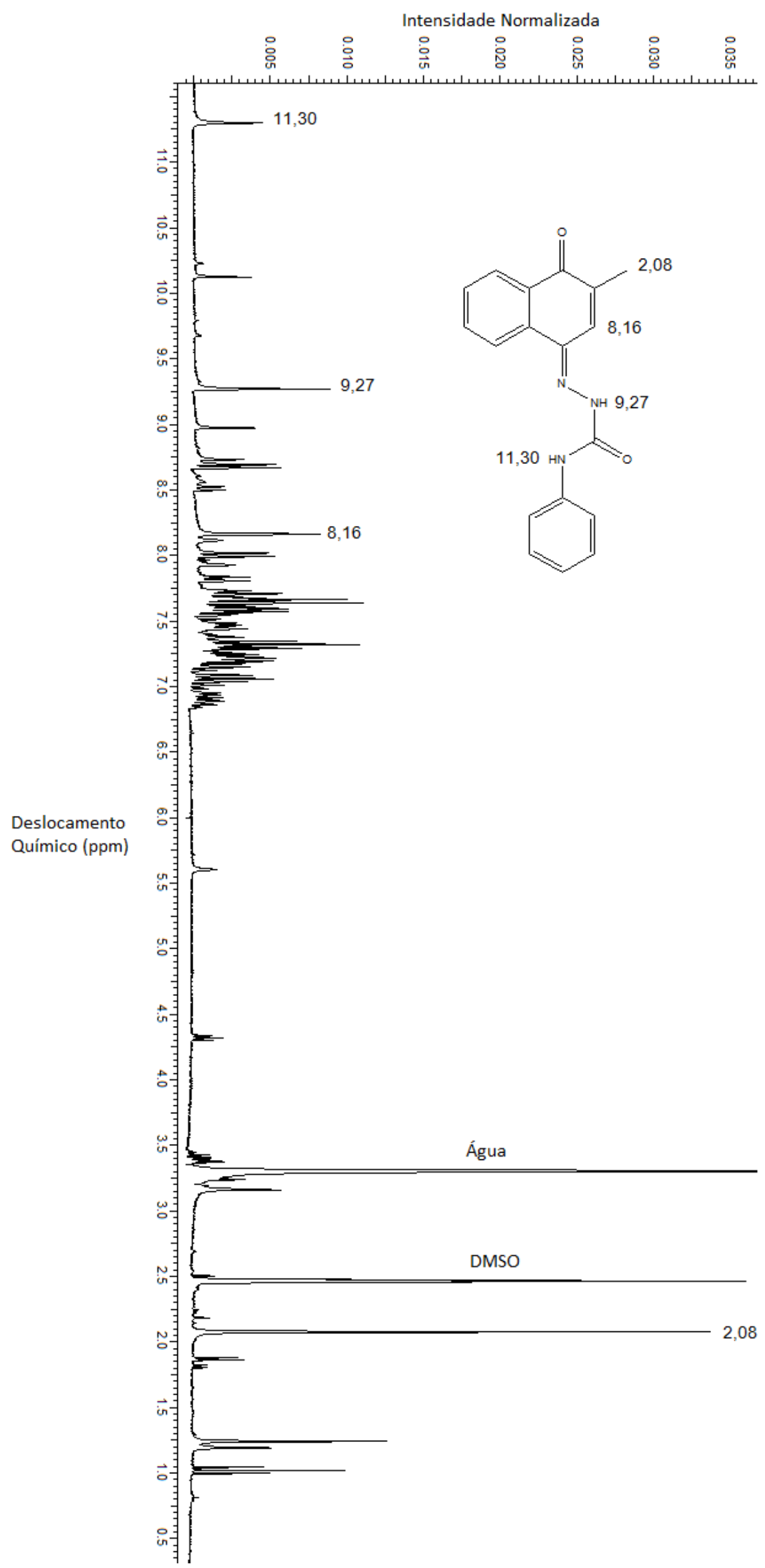

Figura 4.8. Espectro de ${ }^{1} \mathrm{H}$ RMN do ligante K3Phsz. 
No espectro do composto em estudo e observa-se os sinais em $\delta 2,08$ ppm, referente à metila, $\delta 8,16 \mathrm{ppm}$, referente ao $\mathrm{H}$ do alceno, $\delta 9,27 \mathrm{ppm}$, referente ao $\mathrm{NH}$ ligado ao anel aromático e $\delta 11.30 \mathrm{ppm}$, referente ao $\mathrm{NH}$ da amida. Os sinais dos anéis aromáticos não ficaram tão claros, devido à superposição dos mesmos, que se encontram na região entre $\delta 7,0$ ppm a $\delta 8,1$ ppm. 


\section{CONCLUSÕES E PERSPECTIVAS}




\section{Conclusões e Perspectivas}

A partir dos objetivos propostos e dos resultados neste Trabalho de Conclusão de Curso, pode-se concluir que:

I. Foi possível a síntese e elucidação estrutural através da técnica de difração de raios $\mathrm{X}$ de monocristal de uma nova semicarbazona derivada da vitamina K3;

II. Apesar de não ter sido obtido até o momento um complexo metálico inédito com agentes complexantes derivados da vitamina $\mathrm{K} 3$, foi possível observar o comportamento quanto a reatividade desses ligantes e a capacidade de se coordenarem a diferentes íons metálicos;

III. Para complementar e confirmar os dados da elucidação estrutural por difração de raios X de monocristal, também foram feitas análises de espectroscopias na região do infravermelho e do ultravioleta-visível, espectroscopia por ressonância magnética nuclear de hidrogênio, análise elementar e ponto de fusão;

IV. Com o estudo das superfícies de Hirshfeld foi possível comprovar as interações intermoleculares existentes na estrutura do ligante;

Por fim, o presente trabalho possibilitou um maior conhecimento sobre a química de coordenação de ligantes bases de Schiff, com foco na classe das semicarbazonas, demonstrando que o método de difração de raios $\mathrm{X}$ de monocristal é uma análise essencial para a elucidação e determinação de estruturas cristalinas. Como perspectivas, pretende-se aperfeiçoar os estudos apresentados, elaborando a síntese de novos agentes complexantes da classe das bases de Schiff derivados de vitaminas e a obtenção complexos metálicos inéditos, no intuito de realizar testes biológicos para comprovar as possíveis aplicações farmacológicas dessa classe de compostos. 
6. REFERÊNCIAS 


\section{Referências}

1. http://www.chem.qmul.ac.uk/iupac/medchem/ix.html\#m1 (Acessado em 14 de outubro de 2018).

2. Cohen, S. M., Current Opinion in Chem. Bio. 11(2), 2007, 115.

3. Maria, A., Benite, C.; Machado, S. D. P. Química Nova, 30(8), 2007, 2062.

4. C. Orvig, M. J. Abrams, Chem. Rev. 99, 1999, 2201.

5. P.C.A. Bruijnincx, P.J. Sadler, Curr. Opin. Chem. Biol., 12, 2008, 197.

6. Toma, H. E., Química Bioinorgânica e Ambiental, $1^{\mathrm{a}}$ ed., 2015.

7. Guo, Z., Sadler, P. J., Angew. Chem. Int. Ed., 38, 1999, 1512.

8. Ferraz, K. S. O., Silva, N. F., Da Silva, J. G., Speziali, N. L., Mendes, I. C., \& Beraldo, H., Journal of Molecular Structure, 1008, 2012, 102.

9. M.R. Maurya, A. Kumar, A.R. Bhat, A. Azam, C. Bader, D. Rehder, Inorg. Chem. 45, 2006, 1260.

10. Maia, P.I.S.; Nguyen, H. H.; Ponader, D.; Hagenbach, A.; Bergemann, S.; Gust, R.; Deflon, V. M.; Abram, U. Inorganic Chemistry, 51, 20121604.

11. Oliveira , C.G.; Maia, P. I. S.; Miyata, M.; Pavan, F.R.; Leite, C.Q.F.; Almeida, E. T.; Deflon, V. M. Journal of the Brazilian Chemical Society, v. 25, 2014, 1848.

12. Pavan, F.R.; Maia, P.I.S.; Leite, S.R.A.; Deflon, V.M.; Batista, A.A.; Daisy, N.S.; Scott, G.F.; Leite, C.Q.F. European Journal of Medicinal Chemistry, 45, 2010, 1898.

13. M.R. Prathapachandra Kurup, Binu Varghese, M. Sithambaresan, Suja Krishnan, S.R. Sheeja, Eringathodi Suresh, Polyhedron, 2011,70.

14. Tenório, R.P.; Góes, A.J.S.; De Lima, J.G.; De Faria, A.R.; Alves, A.J; De Aquino, T.M., Quim. Nova, 28, 2005, 1030.

15. Terperini, M.L.A. M.R. Santos, V.R.P. Monteiro, Spectroquim. Acta, Part A 51 1995, 1517.

16. N.C. Romeiro, G. Aguirre, P. Hernández, M. González, H. Cerecetto, I. Aldana, S. PérezSilanes, A. Monge, E.J. Barreiro, L.M. Lima, Bioinorg. Med. Chem., 17, 2009, 641.

17. Zhao, Z., Shi, Z., Liu, M., \& Liu, X., Bionorganic \& Medicinal Chemistry Letters, 22(24), 2012, 7730.

18. Li, M. X., Chen, C. L., Zhang, D., Niu, J. Y., \& Ji, B. S., European Journal of Medicinal Chemistry, 45(7), 2010, 3169.

19. Lessa, J. A., Mendes, I. C., Da Silva, P. R. O., Soares, M. A., Dos Santos, R. G., Speziali, N. L., Beraldo, H., European Journal of Medicinal Chemistry, 45(12), 2010, 5671. 
20. Klayman, D. L., Scovill, J. P., Bartosevich, J. F., \& Bruce, J., Journal of Medicinal Chemistry, 26(1), 1983, 35.

21. Bukowski, L., Zwolska, Z., \& Diseases, P., Chem. Heterocyclic Comp. 42(10), 2006, 1358.

22. Finch, R. a, Liu, M., Grill, S. P., Rose, W. C., Loomis, R., Vasquez, K. M., Sartorelli, A. C., Biochemical Pharmacology, 59(8), 2000, 983.

23. Enyedy, Éva A., Zsigó, Éva, Nagy, N. V., Kowol, C. R., Roller, A., Keppler, B. K., \& Kiss, T., European Journal of Inorganic Chemistry, (25), 2012, 4036

24. Chellan, P., Stringer, T., Shokar, A., Dornbush, P. J., Vazquez-Anaya, G., Land, K. M., Smith, G. S., Journal of Inorganic Biochemistry, 105(12), 2011, 1562

25. Quiroga, A. G.; Cubo, L.; Miguel, P. J. S.; Moneo, V.; Carnero, A.; NavarroRanniger, C, 8, 2008, 1183.

26. Ivanovic, I.; Gligorijevic, N.; Arandelovic, S.; Radulovic, S.; Roller, A.; Keppler, B.K.; Tesic, Z.L.; Grguric-Sipkas, Polyhedron, 61, 2013, 112.

27. Castiñeiras, A.; Fernández-Hermida, N.; García-Santos, I.; Gómez- Rodrígues, L., Dalton Transactions, 41, 2012, 13486.

28. Shao, J.; Ma, Z.; Li, A.; Liu, Y. X. C.; Qiang, Z.; Xu, J., Journal of Inorganic Biochemistry, 136, 2014, 13.

29. Affan, M.A.; Chee, D.N.A.; Ahmad, F.B.; Ismail, J.; Yamin, B.H.; Hitman, R.B. Research Journal of Pharmaceutical, Biological and Chemical Sciences, 1, 2010, 158.

30. Zaitseva, A.S.; Arlyapov, V.A.; Yudina, N.Yu.; Alferov, S.V.; Reshetilov, A.N.; Enzyme Microb. Technol. 98, 2017, 43.

31. Yousef Ebrahimipour, S.; Sheikhshoaie, I.; Crochet, A.; Khaleghi. M.; Fromm, K.M.; J Mol Struct. 1072, 2014, 267.

32. Alagesan, M.; Bhuvanesh, N.S.P.; Dharmaraj, N.; Dalton Transactions 42, 2013, 7210.

33. Sutradhar, M.; Kirillova, M.V.; Guedes da Silva, M.F.C.; Liu, C.M.; Pombeiro, A.J.L. Dalton Transactions, 42,2013, 16578.

34. Kathawate, L.; Shinde, Y.; Yadav, R.; Kasabe, U.; Nikalje, M.; SalunkeGawali, S., J. Therm. Anal. Calorim., 115, 2013, 2319.

35. Manikandan, R.; Viswanathamurthi, P.; Muthukumar, M.; Spectrochimica Acta Part A: Molecular and Biomolecular Spectroscopy , 83, 2011, 297.

36. Pelosi, G.; Bisceglie, F.; Bignami, F.; Ronzi, P.; Schiavone, P., J. Med. Chem., 53 (24), 2010, 8765. 
37. Casas, J.S.; Castellano, E.E.; Couce, M.D.; Ellena, J.; Sanchez, A.; Sordo, J.; Taboada, C.; Journal of Inorganic Biochemistry, 100, 2006, 1858.

38. Mustafa, S., Rao, B. U., SurendraBabu, M. S., Raju, K. K., \& Rao, G. N., Chemistry and Biodiversity, 12(10), 2015, 1516.

39. Ferrari, M. B.; Fava, G. G.; Pelizzi, C.; Pelosi, G.; \& Tarasconi, P., Inorganica Chimica Acta, 269(2), 1998, 297.

40. Ferrari, M. B.; Bisceglie, F.; Pelosi, G.; Tarasconi, P.; Dall'Aglio, P. P.; Pinelli, S.; Bergamo, A.; Sava, G., Journal of Inorganic Biochemistry, 98(2), 2004, 301.

41. Kasuga, N. C.; Sekino, K.; Ishikawa, M.; Honda, A.; Yokoyama, M.; Nakano, S., Nomiya, K., Journal of Inorganic Biochemistry, 96(2-3), 2003, 298.

42. McKinnon, J.J.; Spackman, M.A.; Mitchell, A.S., Acta Crystallogr Sect B, 2004.

43. Spackman, M. A.; Jayatilaka, D., CrystEngComm, 2009, 11.

44. Turner, M. J.; McKinnon, J. J.; Wolff, S. K., CrystalExplorer17, 2017.

45. Hahn, T., International Tables for Crystallography, vol. A - Space-Group Symmetry, $2^{\mathrm{a}}$ ed., The International Union of Crystallography, 1987, D. Reudel Publishing Company, Dordrecht. 